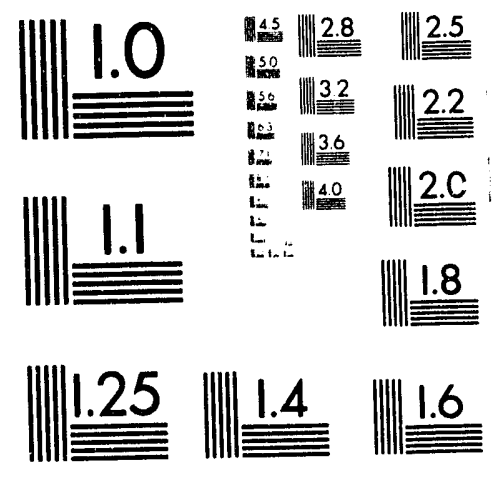



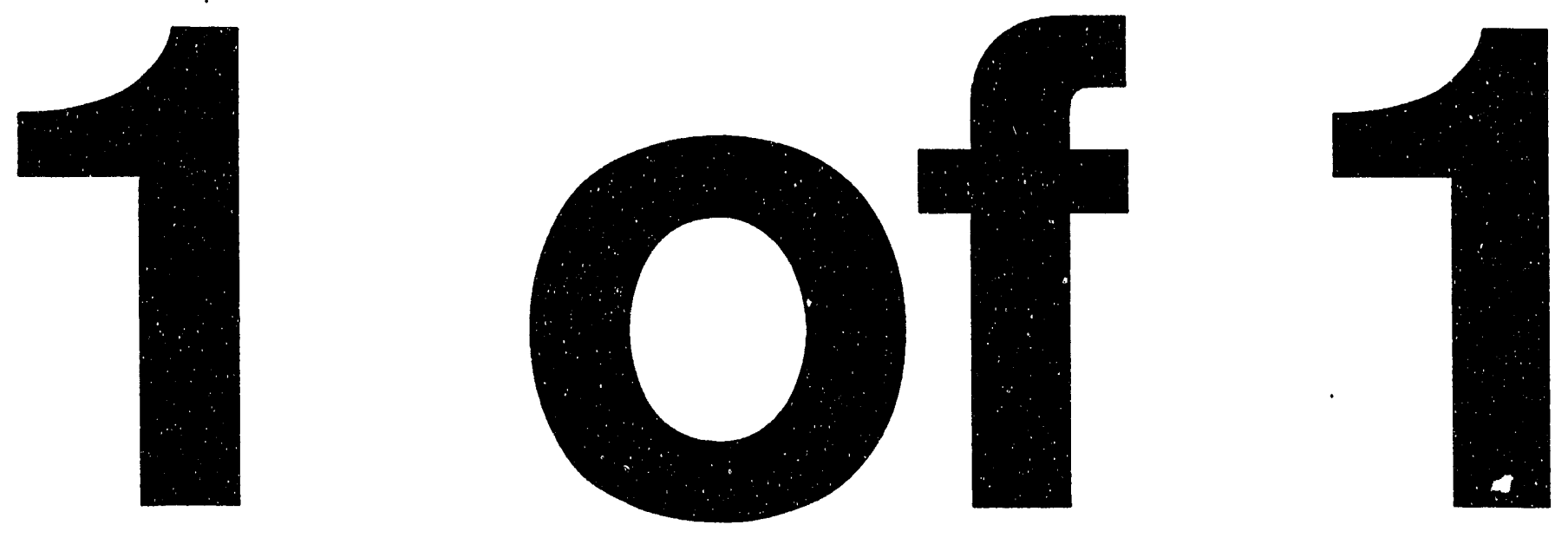


\title{
MODIL Cryocooler Producibility Demonstration Project Results
}

\author{
Gilbert E. Cruz
}

R. Mark Franks

June 24, 1993

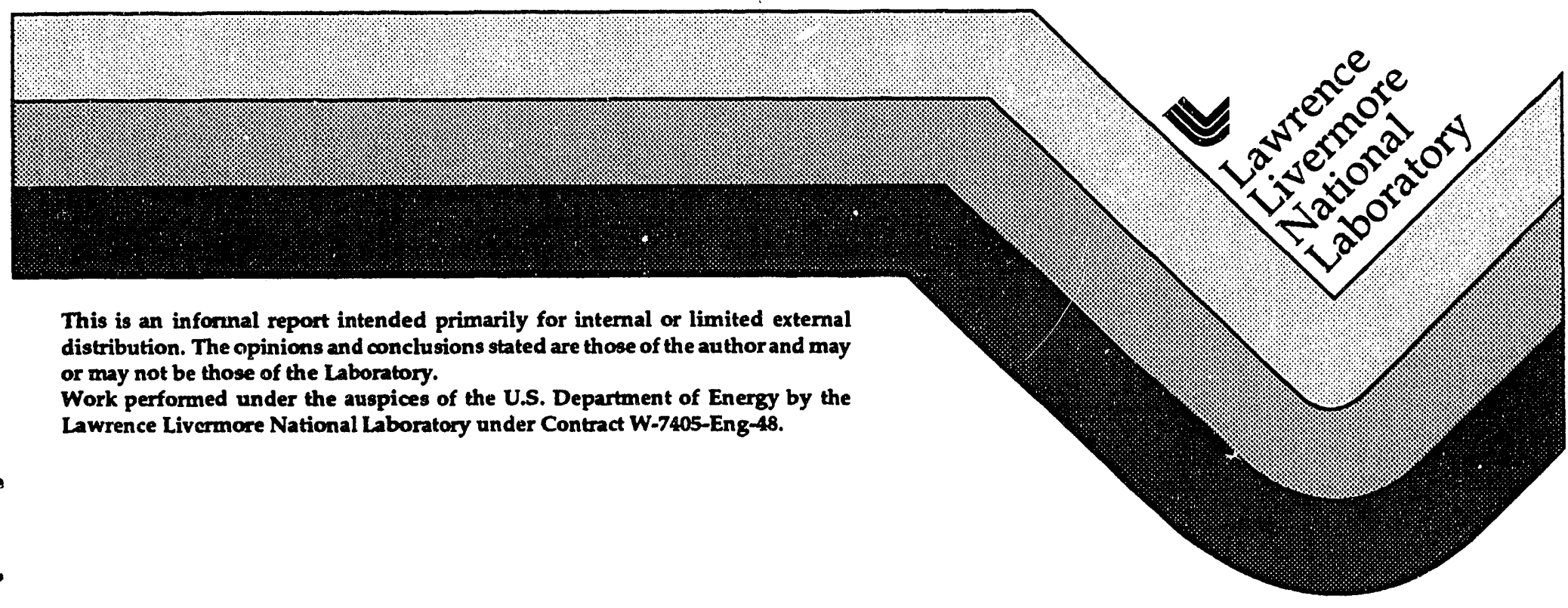




\section{DISCLAIMER}

This document was prepared 2s an account of work sponsored by an agency of the United States Government. Neither the United States Government nor the University of California nor any of their employees, makes any warranty, express or implied, or assumes any legal liability or responsibility for the accuracy, completeness, or usefulness of any information, apparatus, product, or process disclosed, or represents that its use would not infringe privately owned rights. Reference herein to any specific commercial products, process, or service by trade name, trademark, manufacturer, or otherwise, does not necessarily constitute or imply its endorsement, recommendation, or favoring by the United States Government or the University of California. The views and opinions of authors expressed herein do not necessarily state or reflect those of the United States Government or the University of California, and shall not be used for advertising or product endorsement purposes.

This report has been reproduced directly from the best available copy.

Available to DOE and DOE contractors from the Office of Scientific and Technical Information

P.O. Box 62, Oak Ridge, TN 37831

Prices available from (615) 576-8401, FTS 626-8401

Available to the public from the

National Technical Information Service

U.S. Department of Commerce

5285 Port Royal Rd.,

Springfield, VA 22161 


\title{
MODIL Cryocooler Producibility Demonstration Project Results
}

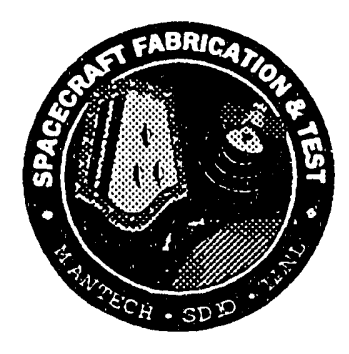

\author{
Gilbert E. Cruz \\ R. Mark Franks
}

\section{Lawrence Livermore National Laboratory Livermore, CA 94551}

June 24, 1993 


\title{
MODIL Cryocooler Producibility Demonstration Project Results*
}

\author{
Gilbert E. Cruz and R. Mark Franks \\ Lawrence Livermore National Laboratory \\ Livermore, CA 94551
}

\begin{abstract}
Cryocoolers are essential components for many spacecraft. We summarize some spacecraft cryocooler requirements and discuss our observations regarding Industry's current production capabilities of cryocoolers. The results of the Lawrence Livermore National Laboratory (LLNL) Spacecraft Fabrication and Test (SF\&T) MODIL's Phase I producibility demonstration project is presented. The current project that involves LLNL and industrial participants is discussed.
\end{abstract}




\section{ACKNOWLEDGMENTS}

The authors wish to acknowledge the participation and cooperation of many involved people in the LLNL MODIL Demonstration Project. In particular, we wish to thank the following individuals:

Messrs. Jack Daniel and Dan Yahraus of Modern Industries.

Messrs. Bill Baschnagel, Dodd Stacy, and Bob Stearns of Creare, Inc.

Messrs. Lou Filios, Ted Macutkiewicz, and Dick Patterson of Westfield Gage.

Messrs. Larry Gresko and Steve Neville of Hughes Aircraft.

The following Lawrence I.ivermore National Laboratory Staff: John Benedict, Terry Benton, Jeff Groth, Dewayne Harkov, Jay Jacobs, Skip Peters, Mike Prokosch, Dick Rose, Kim Shelly, and Don Yordy. 
TABLE OF CONTENTS

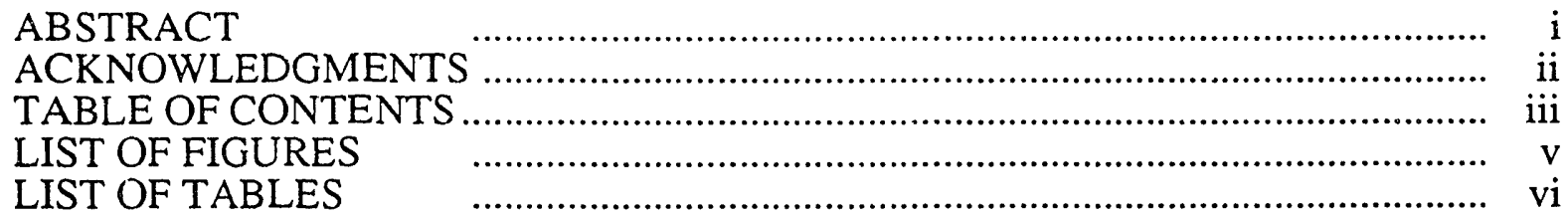

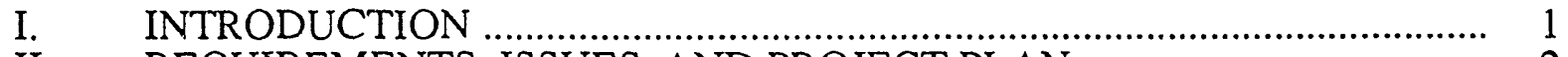

II. $\quad$ REQUIREMENTS, ISSUES, AND PROJECT PLAN .................................. 2

$2.1 \quad$ Spacecraft Requirements............................................................. 2

$2.2 \quad$ Producibility Issues .................................................................... 2

2.3 Demonstration Project............................................................................. 2

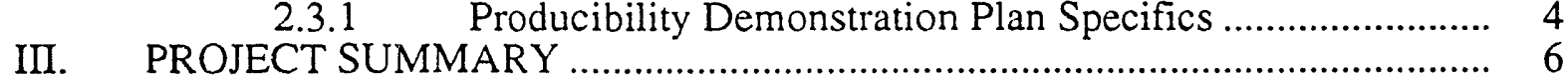

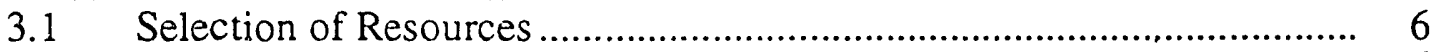

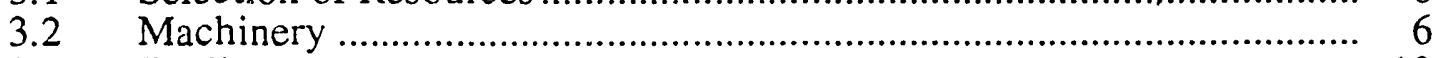

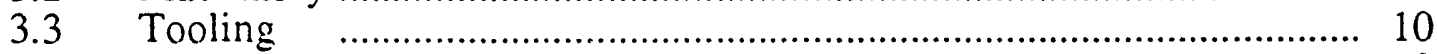

3.4 Measuring Tools .................................................................... 10

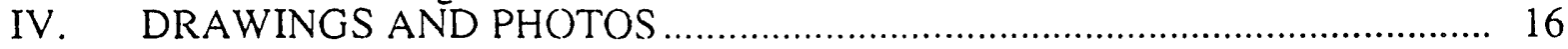

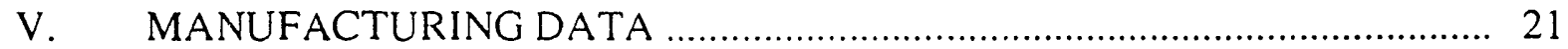

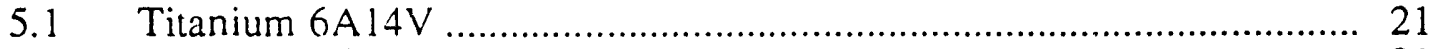

5.1.1 Blank Preparation ....................................................... 21

5.1.1.1 Process .................................................................. 21

5.1.1.2 Recommendation ......................................................... 21

5.1.1.3 Parameters .......................................................................... 21

5.1.2 Rough Machining........................................................ 21

5.1.2.1 Process .......................................................................... 21

5.1.2.2 Parameters ................................................................... 22

5.1.3 Heat Treat Cycle ........................................................... 22

5.1.3.1 Metallographic Investigation ......................................... 22

5.1.3.2 Vacuum Anneal........................................................... 25

5.1.3.3 Alternate Process Investigation-Cryogenic Stabilization..... 25

5.1.3.4 Recommende. on ......................................................... 26

5.1.3.5 Alternate Vacuum Anneal Process (Contractor supplied) .... 26

5.1.4 Datum Machining ............................................................. 26

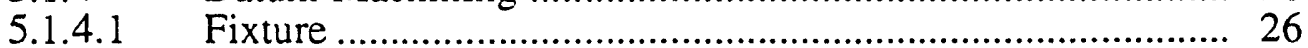

5.1.4.2 Process ................................................................. 26

5.1.4.3 Recommendation ........................................................ 27

5.1.4.4 Parameters ................................................................ 27

5.1.5 Electrical Discharge Machining (EDM) of Inner Feature .... 27

5.1.5.1 Process ........................................................................ 27

5.1.5.2 Recommendation ................................................................. 27

5.1.5.3 Parameters....................................................................... 28

5.1.5.4 Metallographic Investigation ........................................ 29

5.1.5.5 Recommendation .................................................. 34

5.1.6 Finishing of Outer Features........................................... 34

5.1.6.1 Process .......................................................................... 34

5.1.6.2 Alternate Process (Contractor supplied) .............................. 34

5.1.6.3 Recommendation ...................................................... 34

5.1.6.4 Parameters ..................................................................... 34

5.1.7 Inspection ........................................................... 34

5.1.7.1 Diametrical Size ............................................................. 34

5.1.7.2 Runout Measurement Process ............................................ 34

5.1.7.3 Linear Features ............................................................. 37 


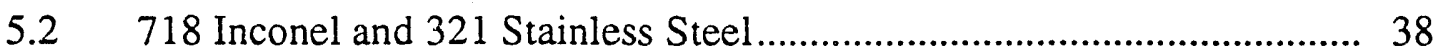

5.2.1 Recommendation ..................................................... 38

5.2.2 Blank Preparation .............................................................. 38

5.2.3 First Roughing Operation (Inconel/Stainless Steel).............. 38

5.2.3.1 Process .......................................................................... 38

5.2.3.2 Parameters .................................................................. 39

5.2.4 Second Roughing Operation (Inconel/Stainless Steel) ......... 39

5.2.4.1 Process ........................................................................... 39

5.2.4.2 Parameters ................................................................... 39

5.2.5 Heat Treat Cycle ............................................................. 39

5.2.5.1 Stainless Steel - Vacuum Anneal ....................................... 40

5.2.5.2 Inconel-Cryogenic Stabilization ............................................ 41

5.2.6 Finishing Operation (Inconel) ................................................. 41

5.2.6.1 Recommendation ......................................................... 42

5.2.7 Finishing Operation (Stainless Steel) .................................... 42

5.2.7.1 Method 1 .......................................................................... 42

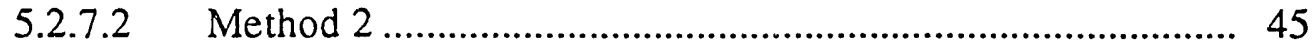

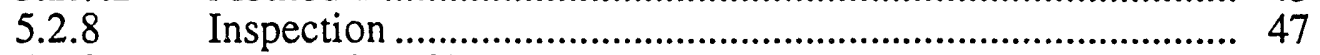

5.2.8.1 Diametrical Size Determination........................................... 47

5.2.8.2 Runout Measurement Process .............................................. 47

5.2.8.3 Linear Feature Verification ................................................... 47

VI. COSTS

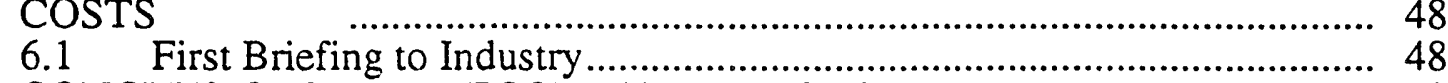

VII. CONCLUSIONS AND RECOMMENDATIONS ……………………….......... 49

VIII. PROJECT CLOSE-OUT MEETING SUMMARIES ........................................... 50

Crear/Westfield Gage/LLNL Demo Project Close-Out Meeting ........................ 51

Hughes Aircraft/Modern Industries/LLNL Demo Project Close-Out Meeting. 54

IX. REFERENCE MATE? IAL …………………......................................... 56

Glossary

References

Distribution List 


\section{LIST OF FIGURES}

Figure 1 Interaction with Industry ....................................................... 3

Figure 2 Titanium (L) and Inconel (R) Demonstration Project Components ....... 5

Figure 3 Hardinge HLV-H 10 inch Toolmaker's Lathes ........................................

Figure $4 \quad$ Agietron Agiecut 200 ....................................................................

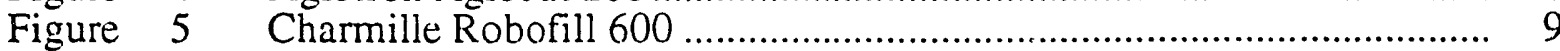

Figure 6 Bendix Indi-Ron Roundness Gage ….............................................. 11

Figure 7 Sheffield Air Gage ................................................................. 12

Figure 8 LaserMike ............................................................................. 13

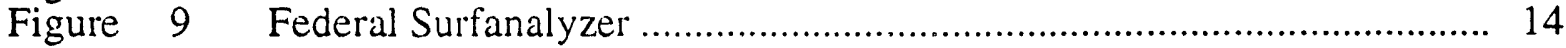

Figure $10 \quad$ OGP Optical Comparator ......................................................... 15

Figure 11 Titanium Demonstration Component Drawing...................................... 17

Figure 12 Inconel/Stainless Steel Demonstration Component Drawing .................. 18

Figure 13 Titanium Demonstration Component ............................................. 19

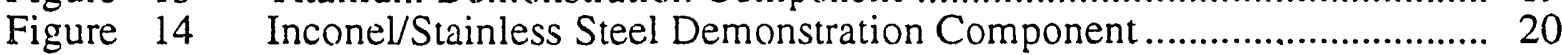

Figure $15 \quad$ Part A-1 -Vacuum Anneal Only ...................................................... 23

Figure $16 \quad$ Part B-1-Cryogenic Stabilization Only .............................................. 23

Figure $17 \quad$ Part C-1-Vacuum Anneal and Cryogenic Stabilization ......................... 24

Figure $18 \quad$ Part D-1-Stock Material ................................................................... 24

Figure 19 Titanium Components Vacuum Anneal Process .................................. 25

Figure 20 Titanium Components Cryogenic Stabilization Cycle.......................... 25

Figure 21 Titanium Components Alternate Vacuum Anneal Process...................... 26

Figure $22 \quad$ Part A-2-Vacuum Anneal and Wire EDM..................................... 30

Figure 23 Part B-2-Cryogenic Stabilization and Wire EDM .......................... 31

Figure $24 \quad$ Part C-2 - Vacuum Anneal Cryocooler-Wire EDM.......................... 32

Figure 25 Part D-2-Stock Material and Wire EDM ..................................... 33

Figure 26 Polar Chart .................................................................................... 36

Figure $27 \quad 321$ Stainless Steel Vacuum Anneal Cycle ......................................... 40

Figure $28 \quad 718$ Inconel Cryogenic Stabilization Cycle ........................................ 41

Figure $29 \quad$ Floating Center.......................................................................... 44

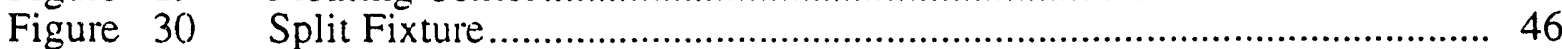

Figure 31 Hours/Component/Phase Comparison ........................................... 48 


\section{LIST OF TABLES}

Table 1

Table 2

Table 3

Table 4

Table 5

Table 6

Table 7

Table 8

Table 9

Table 10

Table 11

Table 12

Table 13

Table 14

Table 15

Table 16

Table 17

Table 18

Table 19

Table 20

Table 21

Table 22

Table 23
Blank Facing Operations ............................................................... 21

Blank Drilling Operation ............................................................ 21

Rough Machining ...................................................................... 22

Processes Identification Metallographic Samples.................................. 22

Datum Machining ......................................................................... 27

Power and Wire Settings_-Agietron 200 ......................................... 28

Flushing Parameters-Agietron 200 .............................................. 28

Geometric Parameter Setting-Agietron 200 ........................................ 29

Finishing-Outer Prolile................................................................ 34

First Roughing Operation_Inconel ...................................................... 39

First Drilling Operation_-Inconel ................................................... 39

First Roughing Operation-Stainless Steel ..................................... 39

First Drilling First — Stainless Steel .................................................. 39

Second Roughing Operation-Inconel Component ............................. 39

Second Roughing Operation-Stainless Steel ..................................... 39

Finishing Bore Parameters_Inconel (Method 1) .................................. 41

Finish Outer Features_-Inconel (Method 1) ........................................ 42

Grinding Bore Parameters-Inconel (Method 2) ................................... 42

Stainless Steel Component (Method 1) ............................................... 43

Finish Bore Parameters-Stainless Steel (Method 1) ........................... 43

Outer Features Finishing Parameters-Stainless Steel (Method 1) ....... 43

Bore Finishing Parameters-321 Stainless Steel (Method 2) ................ 45

Outer Feature Finishing Parameters (Method 2) ..................................... 45 


\section{INTRODUCTION}

The production of large quantities of spacecraft needed by SDIO will require a cultural change in design and production practices. Low rates production and the need for exceedingly high reliability has driven the industry to custom designed, hand crafted, and exhaustively tested satellites. These factors have mitigated against employing design and manufacturing cost reduction methods commonly used in tactical missile production.

Additional challenges to achieving production efficiencies are presented by the SDI spacecraft mission requirement. IR sensor systems, for example, are comprised of subassemblies and components that require the design, manufacture, and maintenance of ultra precision tolerances over challenging operational lifetimes. These IR sensors demand the use of reliable, closed loop, cryogenic refrigerators or active cryocoolers to meet stringent system acquisition and pointing requirements. Although a stable production base exists for small tactical IR coolers, a domestic base for cryocoolers of the capacity and durability required by SDI satellites does not currently exist. MODILs were established by USAF Lieutenant General Abrahamson in response to his initiatives to mitigate risk and cost escalation of SDIO systems. He wanted to apply proven accelerated approaches such as concurrent engineering to reduce production risks and costs for SDIO. MODILs have grown from a concept to an essential part of the SDIO Producibility and Manufacturing Program, and are a coalition of government, industry, and university participants working together to develop and demonstrate new production and automation processes for current, emerging, and leapfrog product technologies in SDI enabling technology areas ${ }^{1}$. Through the integration of production R\&D efforts in non-proprietary locations, advanced processing and production technologies can be demonstrated and transferred to industry more expediently and cost effectively than by current industrial practices.

MODILs have two salient objectives:

- Identify and implement high payoff producibility thrusts to reduce production risks and costs.

- Develop and transfer to industry emerging production and manufacturing technologies to achieve "pre-planned" product improvements.

This report describes the results of the LLNL MODIL Producibility Demonstration Project. 


\section{REQUIREMENTS, ISSUES, AND PROJECT PLAN}

\section{$2.1 \quad$ Spacecraft Requirements}

Cryocoolers are key components on which spacecraft depend. Simply stated, a cryocooler is a refrigerating engine that uses a working fluid, helium, for a recuperative generator or for a Stirling engine, to cool the spacecraft components. A cryocooler uses a displacer to push compressed gas isochorically from the warm region, where it is compressed, through the regenerator into the cold region where the compressed gas is expanded isothermally, does work on the piston, and produces refrigeration. Although several different concepts and designs exist, the current spacecraft cooler is based on a Split Stirling design.

Cryocoolers provide essential cooling capability for sensors/seekers, cryogen storage, system thermal management, superconducting devices, cold electronics, and super computers. In order to provide adequate cooling capability, unresolved technical issues need to be addressed and resolved.

Several DoD and NASA cryocooler candidates are at development or prototype demonstration stages. Both NASA and DoD have mission needs for cryocoolers of equal or higher capacity.

Operational experience with satellite cryocoolers has been limited and no appreciable life has been accumulated on most coolers.

\section{Producibility Issues}

The salient cryocooler producibility issues are as follows:

- Develop and demonstrate space qualifiable cryocoolers. (This is the generic issue addressed by the MODIL.)

- Build a cryocooler that generates extremely low vibration. (This is a precision alignment and component fabrication issue.)

- Achieve low weight, input power and volume. (These are critical design and performance parameters.)

- Attain low component and assembly contamination, which must be mitigated early in the system assembly phase. (These are process procedure issues.)

- Achieve high quantity component and assembly producibility. (These are endproducts of the MODIL thrust area effort.)

- Obtain a high system reliability during operation. (This is an issue dependent on those preceding.)

- Readily and reliably integrate the cryocooler system with the spacecraft systems.

\section{3}

\section{Demonstration Project}

Establishing and implementing a producibility plan, such as for cryocoolers, require a series of events to take place in order to be successful, refer to the plan specifics on page 7. Each aspect of the process demands close interaction and cooperative effort from industry. A flow chart depicting this process is shown in figure 1.

The primary contractors were visited with the intent of reviewing and identifying the salient cryocooler producibility issues that are inhibiting cryocooler production. Since the Standard Spacecraft Cryocooler (SSC) contracts were well underway, and the Air Force and Phillips Laboratory needed to understand what they were receiving from the two contractors, the project focused on producibility issues for the two SSC designs. 


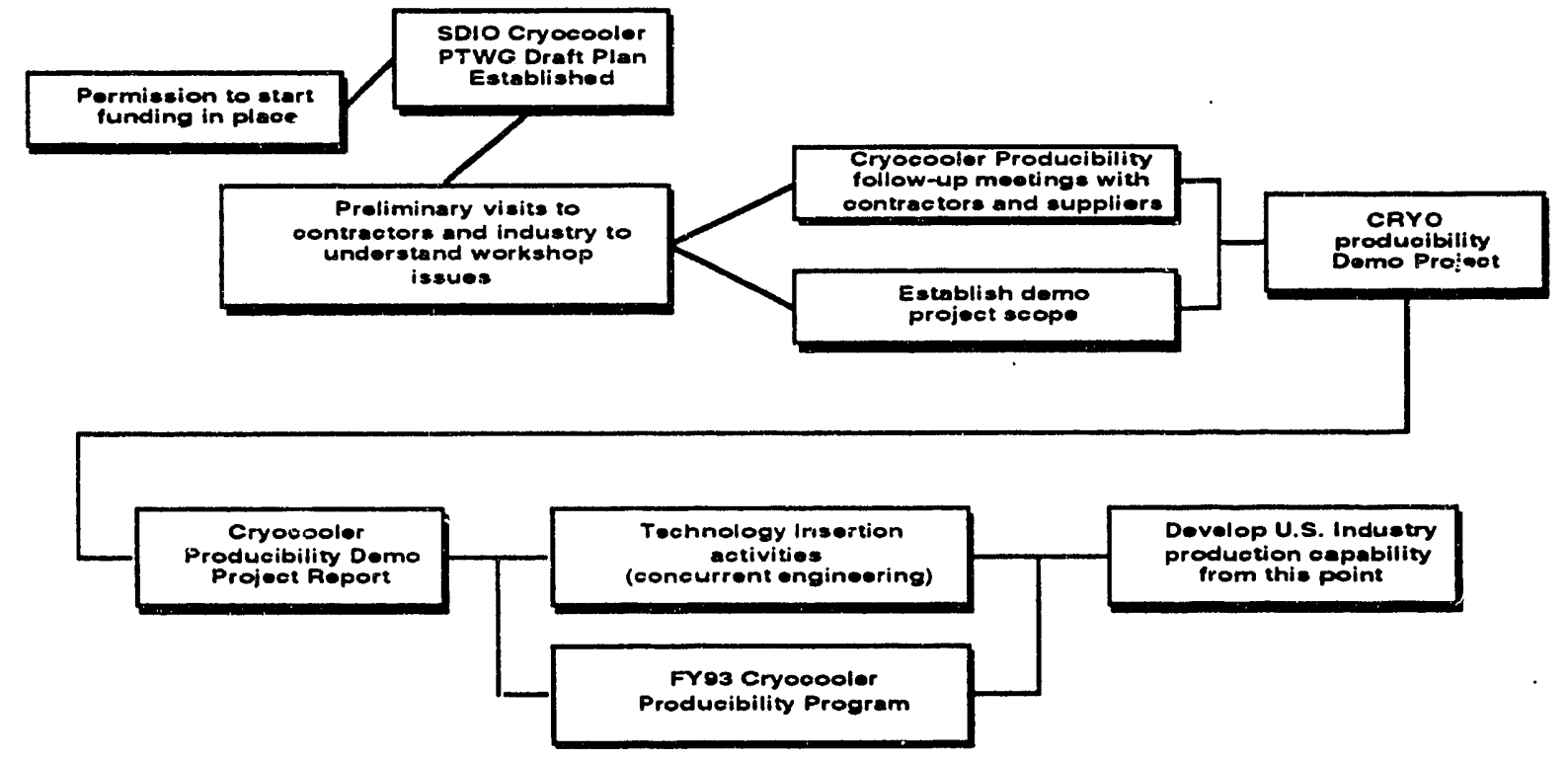

Figure 1 Interaction with Industry 
The producibility demonstration project was designed to demonstrate the necessity for implementing concurrent engineering techniques in the design and production of cryocoolers. Concurrently working production problems with the suppliers, provide the catalyst that facilitates the technology transfer needed to enhance their production capability. By focusing the effort on both the cryocooler developer's design and the supplier's manufacturing approaches, manufacturability can be achieved in real time and disseminated throughout more of industry, through these suppliers who make components for many other companies. The manufacturing supplier effort generates a more far-reaching effect within industry than a single contractor.

\subsubsection{Producibility Demonstration Plan Specifics}

- Agree on project component to produce (LLNL, prime contractor, supplier). The purpose is to solve a common problem.

- LLNL Manufacturing Support Group forms a producibility team.

- Evaluate manufacturing supplier capabilities (LLNL. Producibility Team) with contractor and supplier personnel.

- Put contracts in place with contractors to enable effort to continue at LLNL, the contractors, and at contractor's manufacturing suppliers.

- Establish a production sequence (@ LLNL).

- Establish a process plan (@ LLNL).

- Implement the process plan (@ LLNL).

- Develop inspection techniques (@LLNL). (Implemented before establishing the production sequence)

- Validate the process (includes: inspection techniques, data acquisitions, etc.)

- Establish production machine tool and inspection set ups.

- Implement a production run (includes: in-process inspection, data acquisition).

- Finish part production - 100\% inspection (@ LLNL).

- Maintain the producibility team (for continuity) when moving to supplier facility.

- Supplier personnel acquire hands-on lead with LLNL personnel as consultants to them (@ supplier's).

- Work with suppliers to enhance their machines where applicable (@ supplier's).

- Develop and implement the producibility process (@ supplier's).

- Produce the end product:

- Process detail planning

- Process summary documentation

- Parts delivery

- Supplier capable of utilizing new technology

- Hold project close-out meetings with contractors and suppliers.

Two components were selected for this demonstration project, (figure 2), both of which have the thin to thick wall interface and close tolerance features, to assess producibility and develop a manufacturing plan to be transferred to the participants. Titanium and Inconel were the materials to be used for these items. Stainless steel was substituted for the Inconel when thorough process development attempts did not result in the desired geometries from Inconel. Findings on the three materials, Titanium, Inconel, and Stainless Steel are reported in section V of this report. 


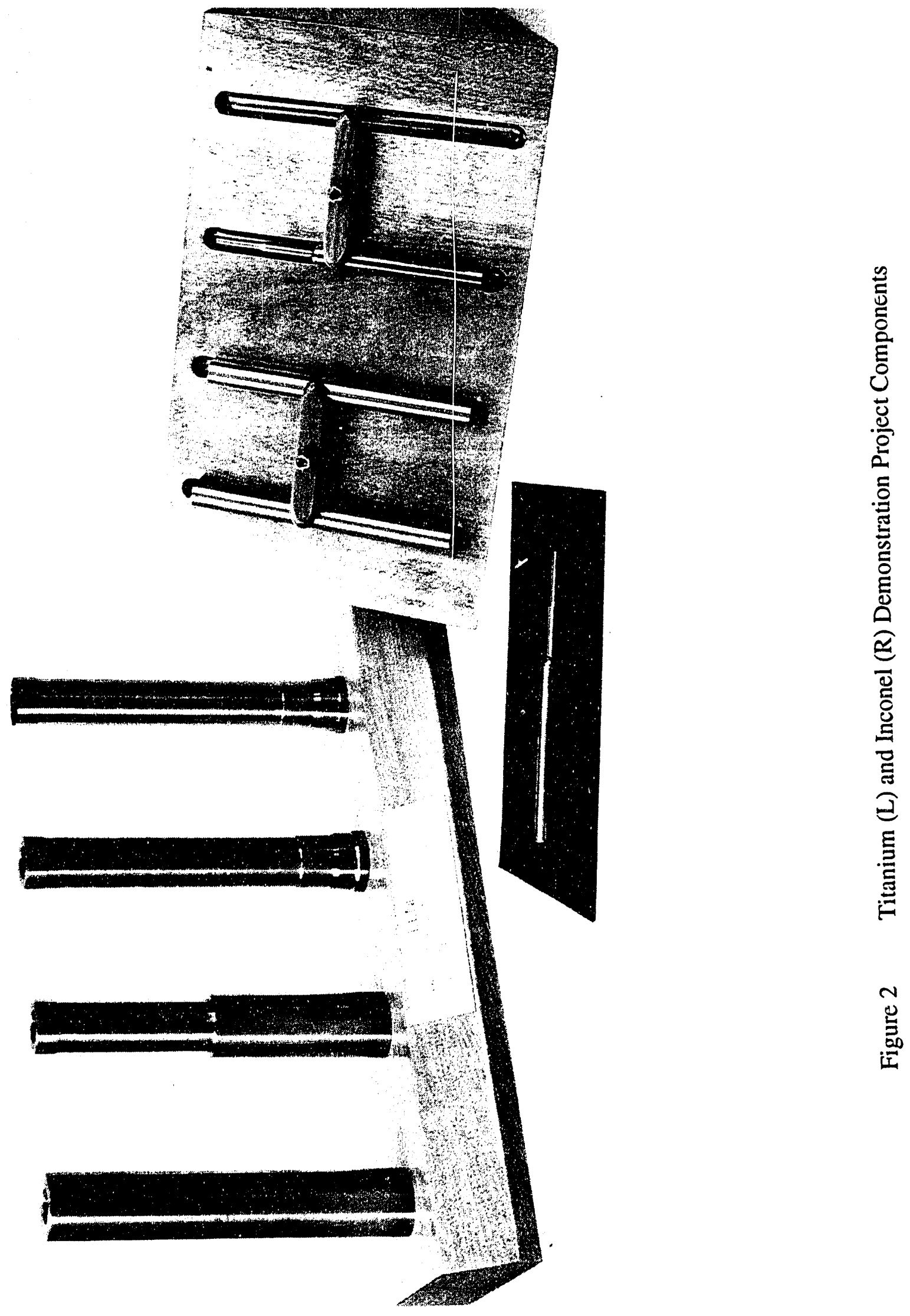




\section{PROJECT SUMMARY}

3.1

\section{Selection of Resources}

The exacting natures of the demonstration components require that skilled crafts people be used throughout the entire operation. The importance of this "soft technology," the people involved, must not be underestimated. The team concept was shown to be very effective in the development of processes and the manufacturing of these components. The precision and accuracy of these components rely on the thorough planning and deliberate execution of processes by these skilled individuals.

Machinery and tooling resources representative of those possessed by, or commercially available to, the participating vendors were chosen in an attempt to develop processes that will be readily assimilated by the private sector. The issue continues to be the utilization of appropriate resources to assure accuracy and precision in production.

\section{2}

Machinery

Common CNC lathes and conventional lathes were used in the roughing operations of all components.

Hardinge HLV-H 10 inch Toolmaker's Lathes (figure 3) were used in roughing and finishing operations.

Agietron Agiecut 200 (figure 4) and Charmille Robofill 600 (figure 5) wire EDM machines were used to finish the inner features.

Trim-Sol, the coolant used by LLNL personnel for this project, contains chlorine; it is one of several substances restricted in the manufacture of aerospace hardware. The aggressive project schedule and the generic non-flight natures of the demonstration components were primary factors in this decision. New-Lube is one acceptable alternative. 


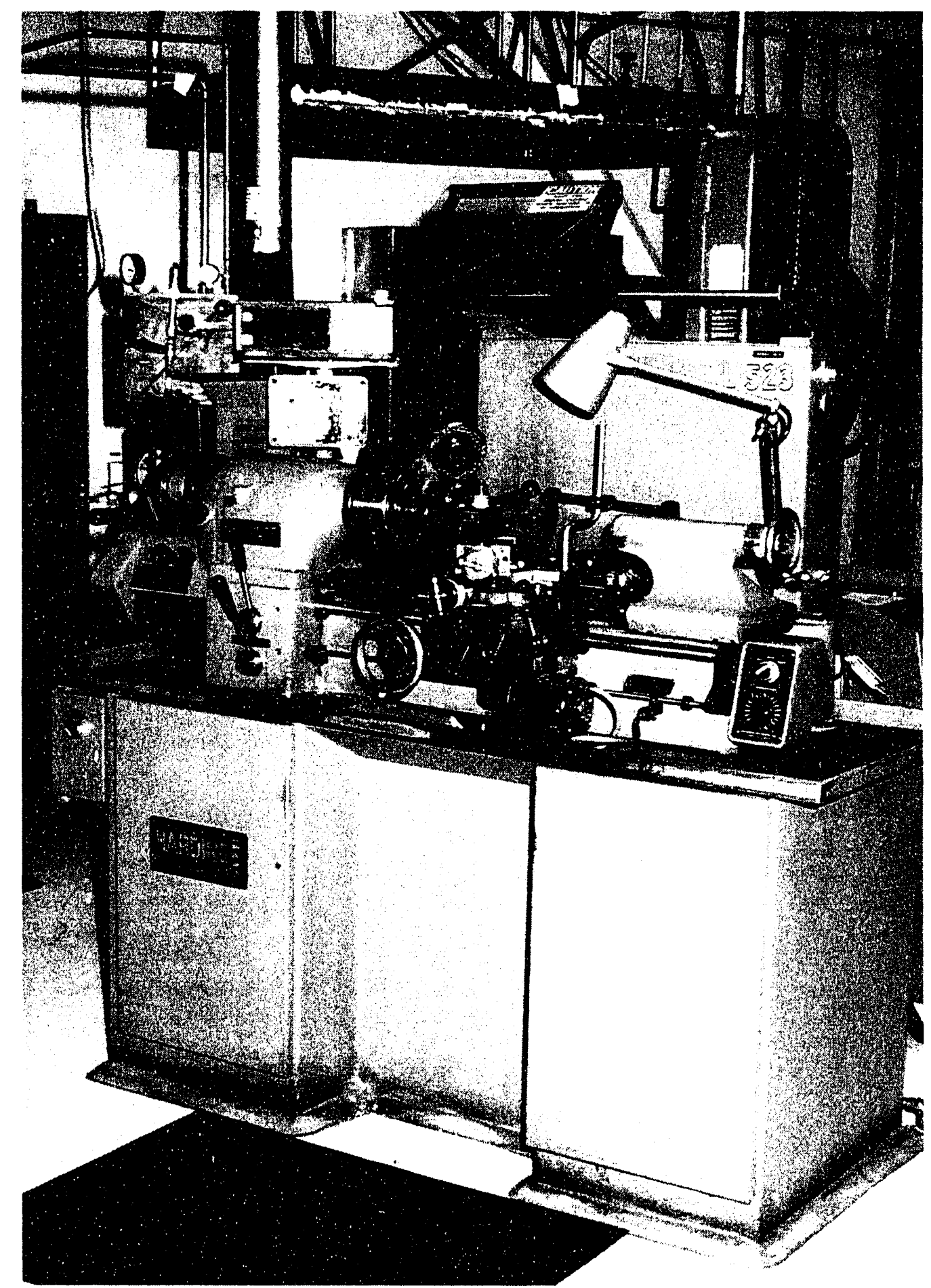

Figure 3 Hardinge HLV-H 10 inch Toolmaker's Lathes were used in the development of turning operations. 


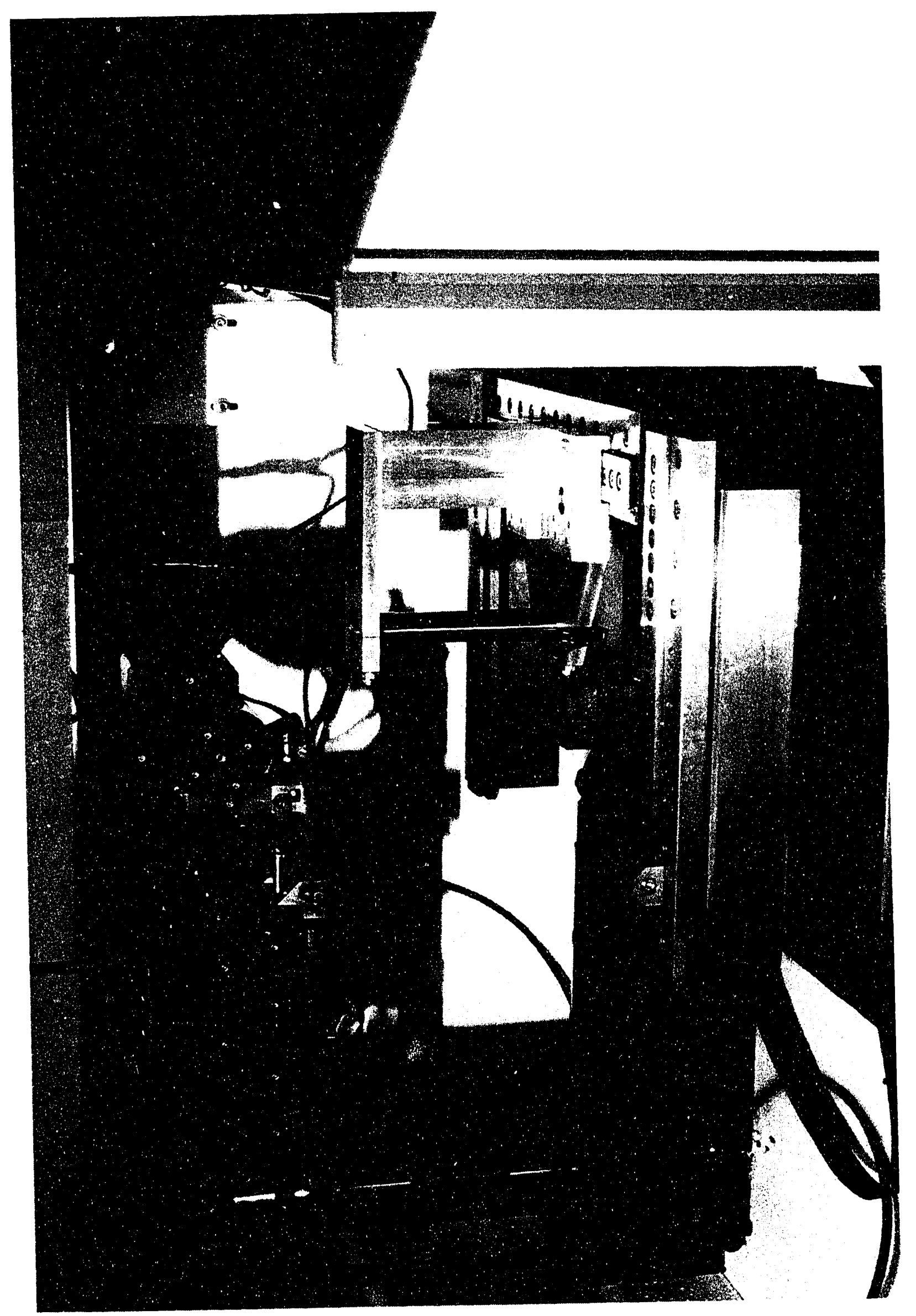

胥兽

둥

些充

证 3

0.00

푸의

능응

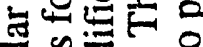

웡 응

㐘

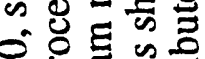

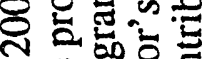

․ㅝㅇ융

更

Q0.

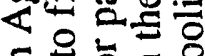

ธ웡.

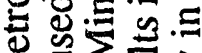

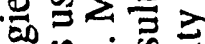

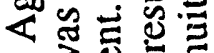

is 3

용응

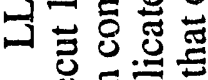
을 음 <

$\forall$ is

능웡용 流》崖导 


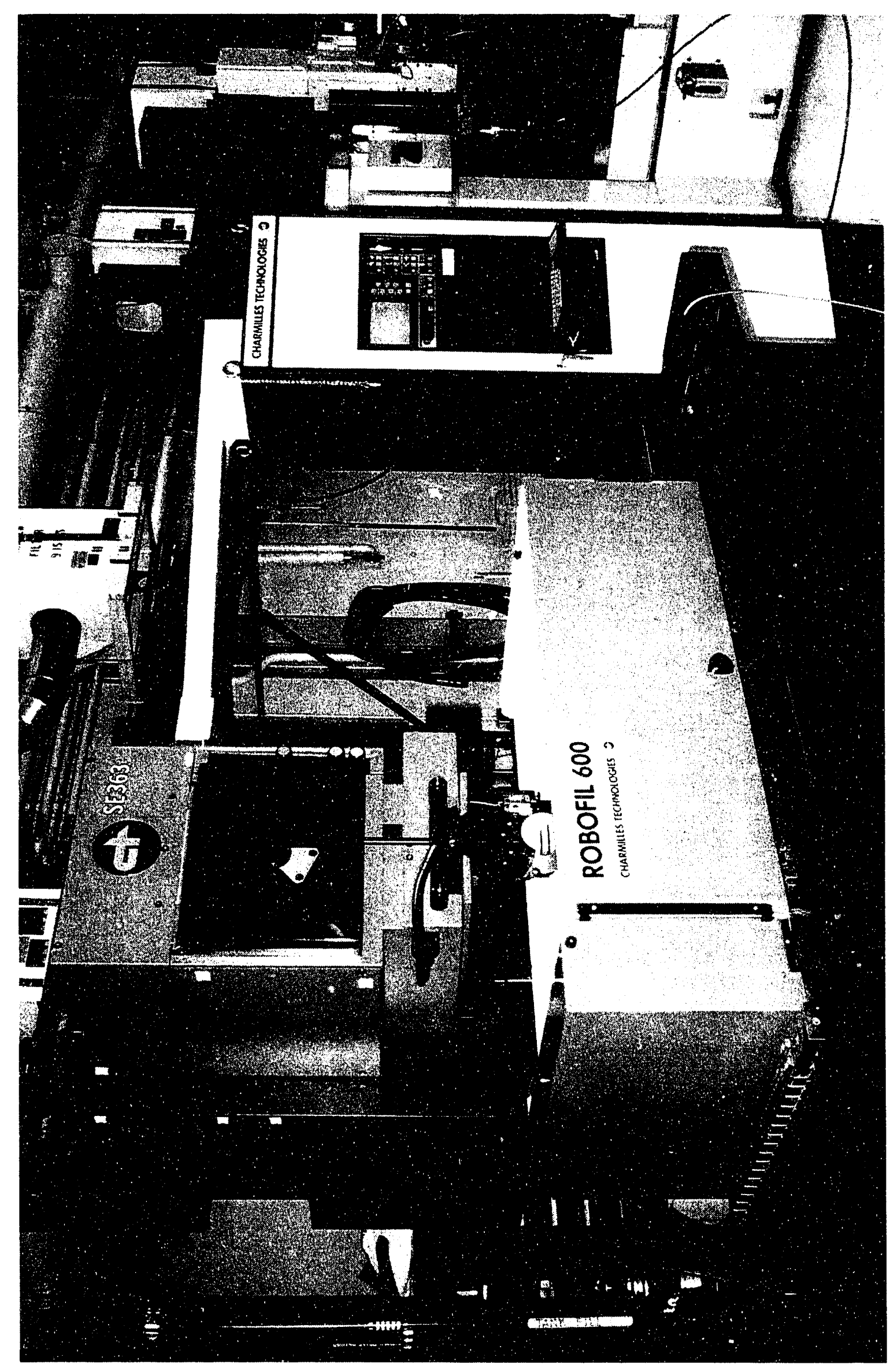

$\varepsilon \div 5$

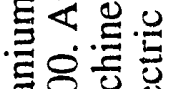

월용

릴일

政正

응 $\dot{0}$ 000 응

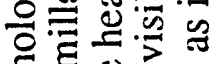

重 छछ可 $\sum .000$

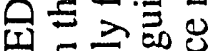

世 $5 \overline{0}$

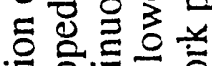

可讨

可 0

뭉 政

क ⿻

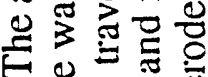

○े

\&.7.

르이

的氖氖

늘

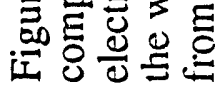


Tooling consists of "off-the-shelf" resources; the exception being the after market grinding of high back rake on the VC-29 carbide inserts used for finishing the outer profiles of the Inconel and Stainless steel components (detailed in section 5.2). This high back rake produces better chip flow characteristics resulting in less $100 \mathrm{l}$ pressure on the part. Stresses induced in the part are minimized with this type of tool configuration, therefore, providing a more geometrically stable component.

The nomenclature identifying carbide insert lathe tooling generally contains three segments, one alpha, one numeric and the third, generally, alphanumeric. The alpha portion pertains to the insert's geometry. The numeric segment identifies the size, thickness, and tool nose radius of the insert, while the alphanumeric portion defines the grade of carbide used in the cutting tool. This designation varies by manufacturer.

\section{$3.4 \quad$ Measuring Tools}

Measuring tools available at LLNL were used to verify part sizes and geometric features. The function of the primary inspection tool, the Bendix Indi-Ron roundness gage (figure 6) can be duplicated by commercially available tools. The Federal Formscan Circular Geometry Gage and Rank Taylor Hobson's Talyrond 250 are commercially available for approximately $\$ 100 \mathrm{~K}$. The precision and accuracy requirements of the demonstration components dictated the use of this type of inspection equipment.

Sheffield gaging (figure 7) was purchased and evaluated to determine the effect of the air pressure on the thin wall components during inspection. Test results revealed air gaging as a viable option for the determination of internal size. Air gaging exhibited no appreciable distortion of the part geometry when employed during inspection.

A LaserMike (figure 8) brand micrometer was purchased for $\$ 6 \mathrm{~K}$. This inspection equipment provides a non-contact method of measuring outer diameters in a precise manner. Potential human influence and variation are negated with this tool, because the tool uses a laser light transmitter and receiver to establish size.

A Federal Surfanalyzer was adapted to determine straightness of some inner features for the tight tolerances specified (figure 9).

An OGY brand optical comparator was used to provide non-contact linear verification of outer features (figure 10). 


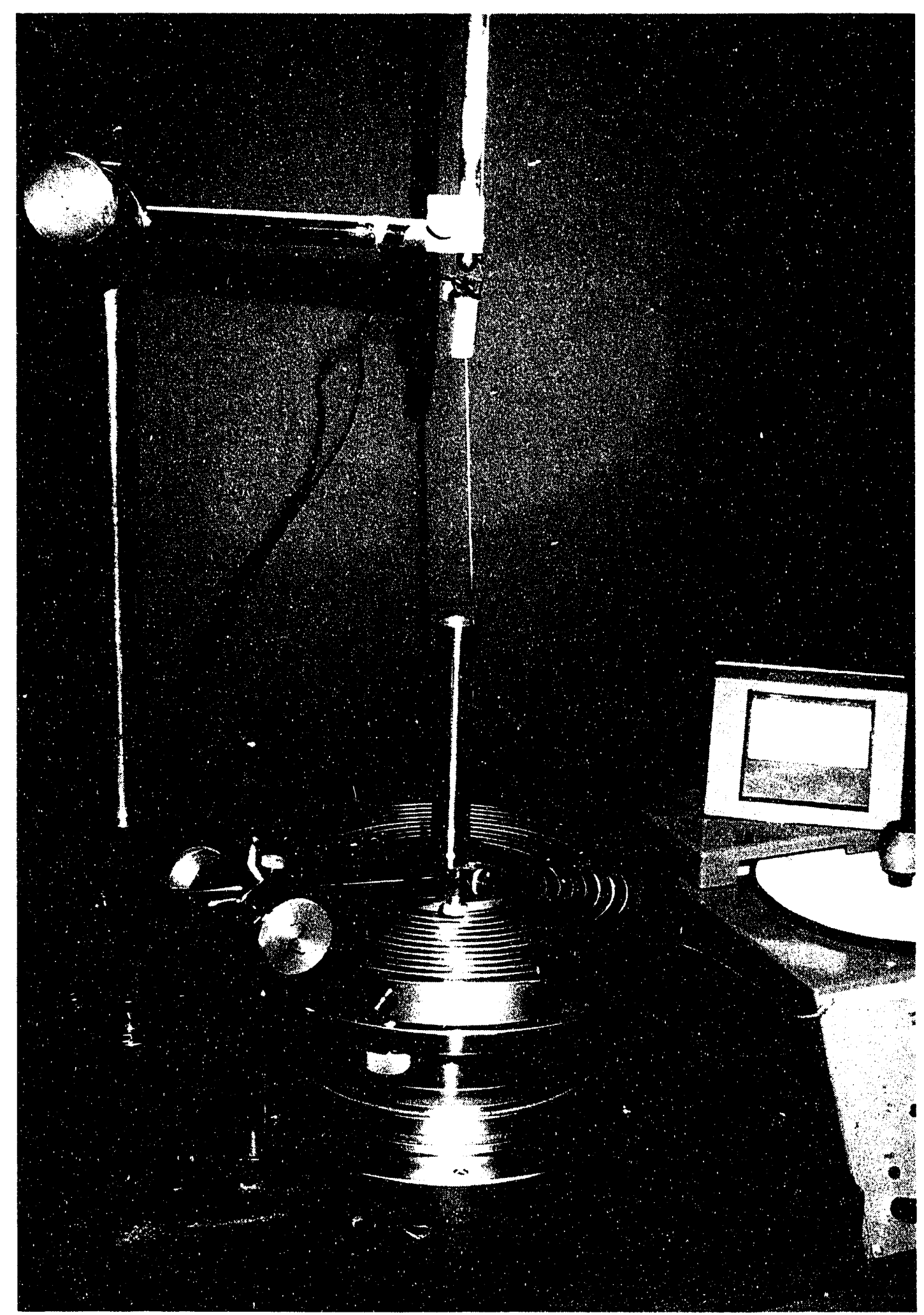

Figure 6 The Bendix Indi-Ron roundness gage was used to measure and document roundness, a total runout factor, of the demonstration components. Note the four inch probe in position to take the first inner diameter trace on the Titanium component. A similar process was used on the Inconel and Stainless Steel components. 


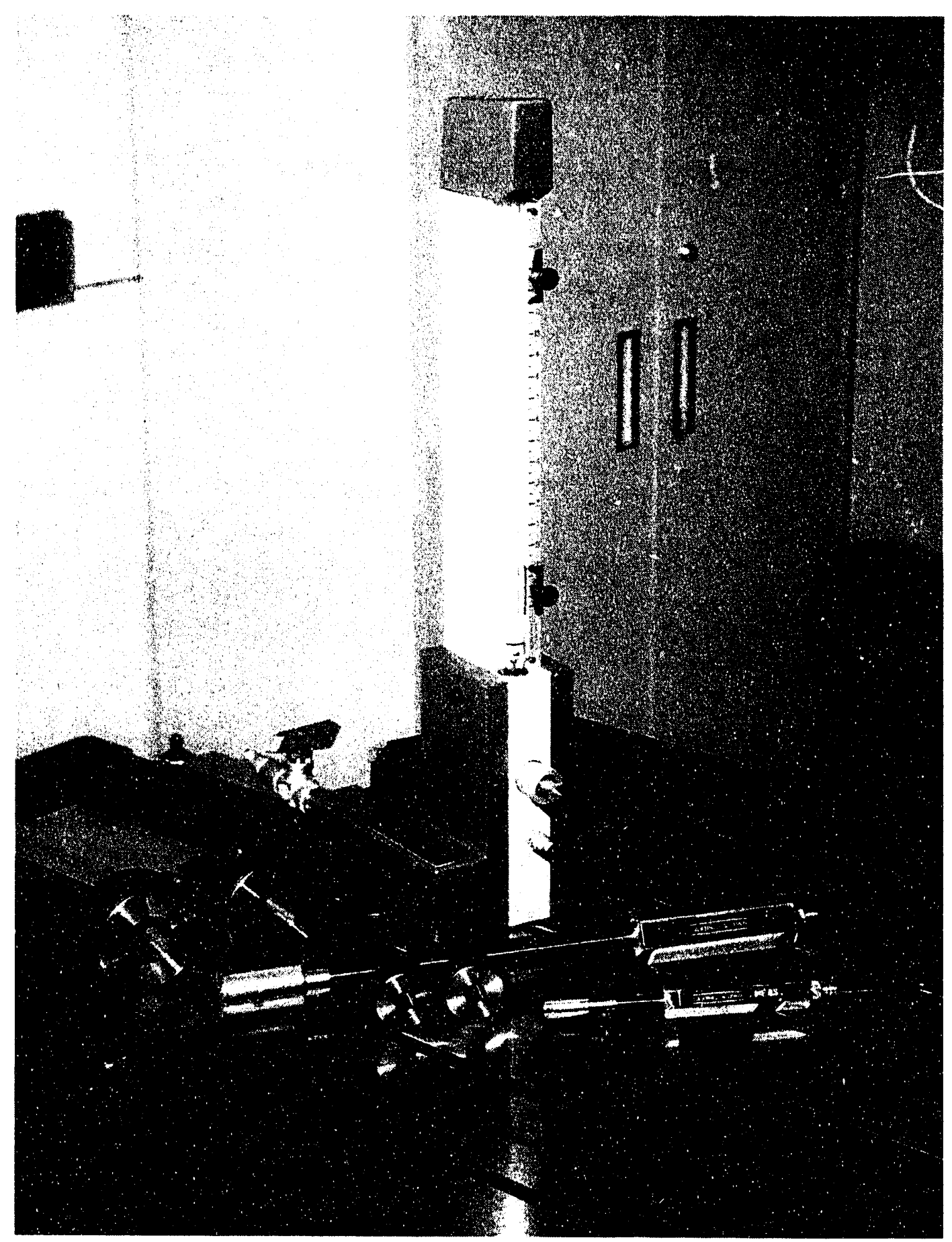

Figure 7 The Sheffield Air Gage was used to determine inner diameter sizes. This process of measurement assures minimal impact to the thin wall portion of the demonstration components. 


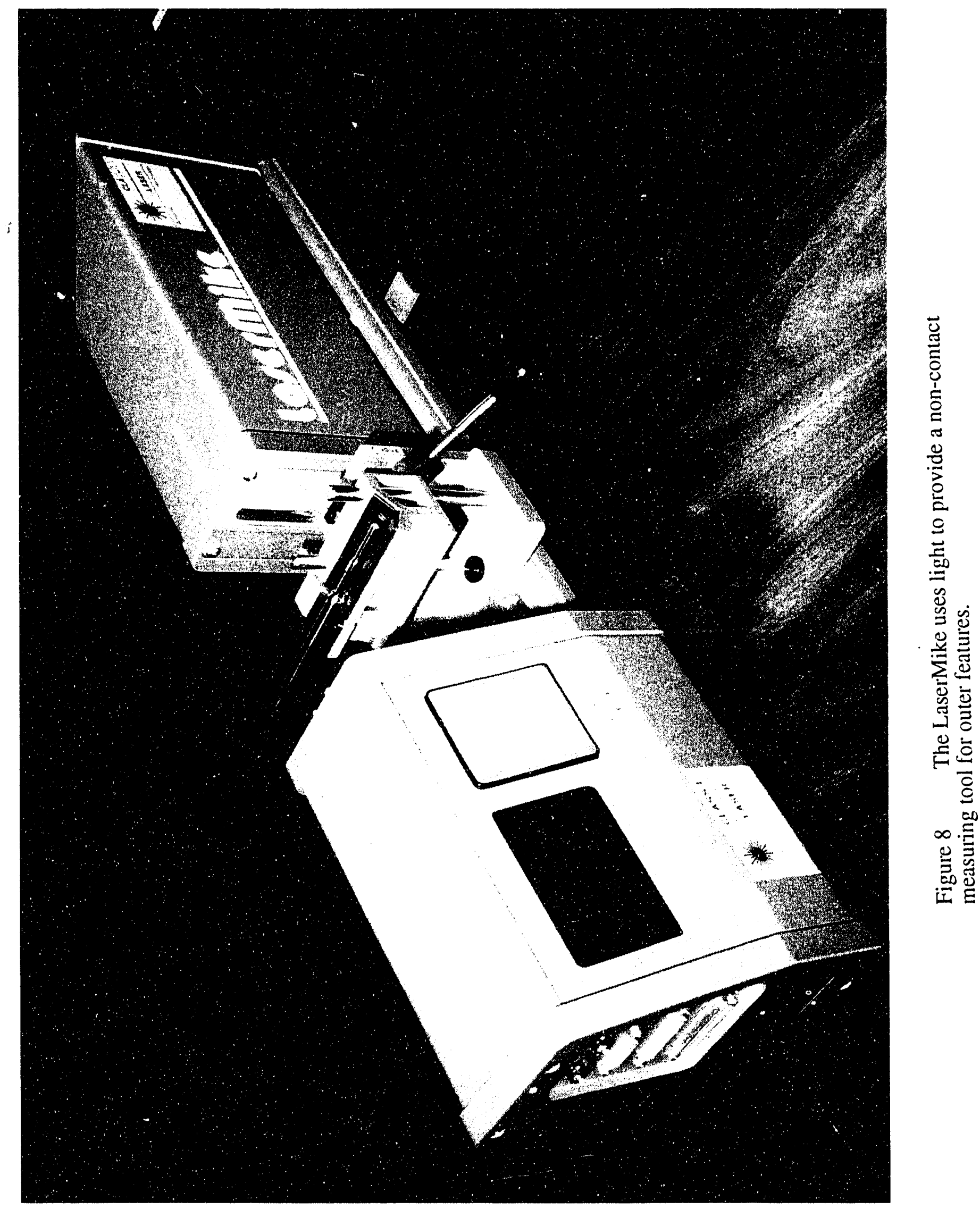




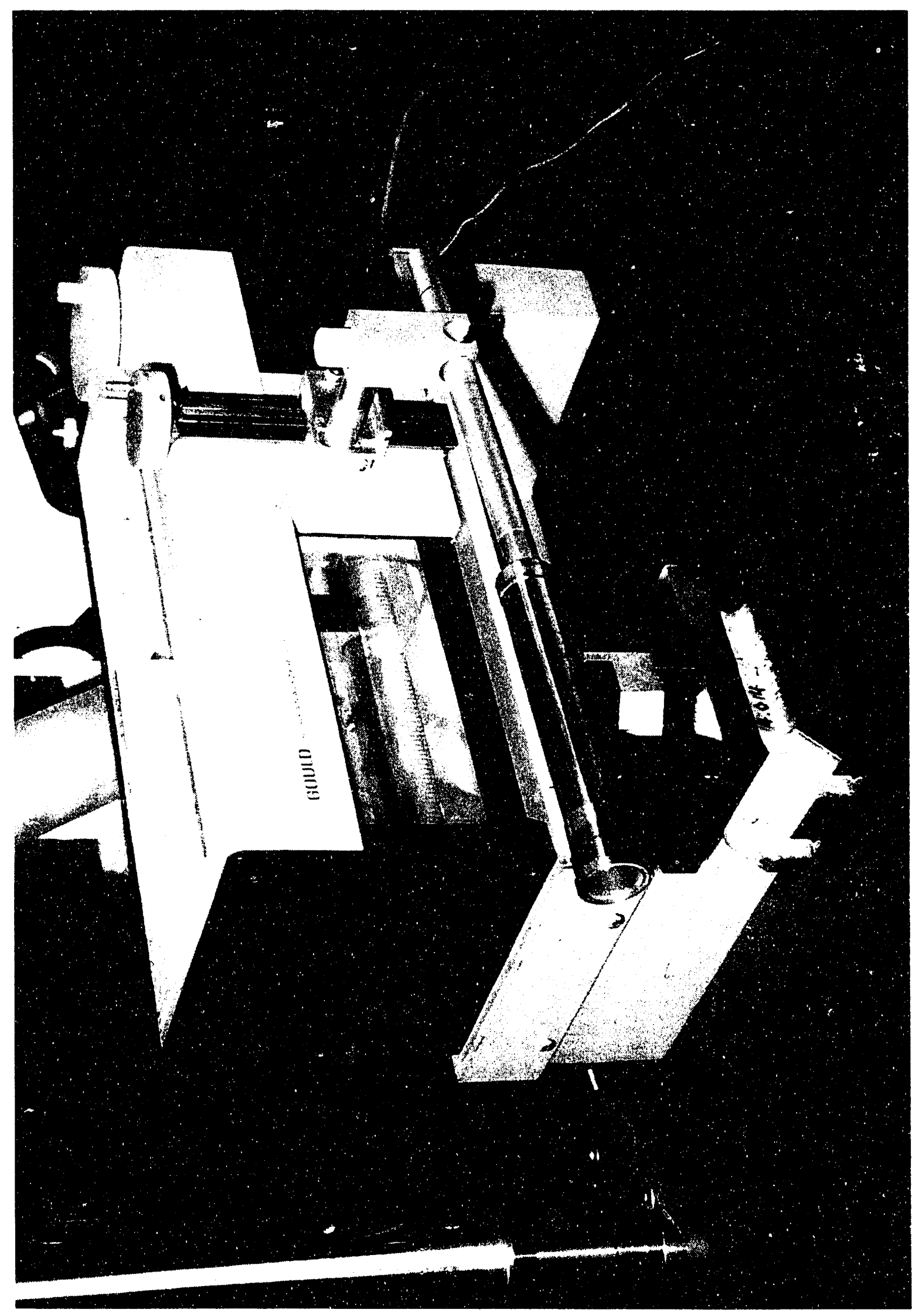

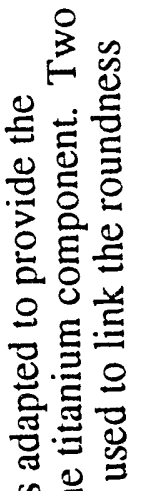

З气

ब유

층

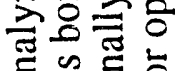

䨔沙。

光畐号

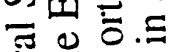

호응

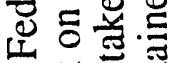

《部 웡

过

a导吉

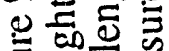

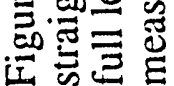




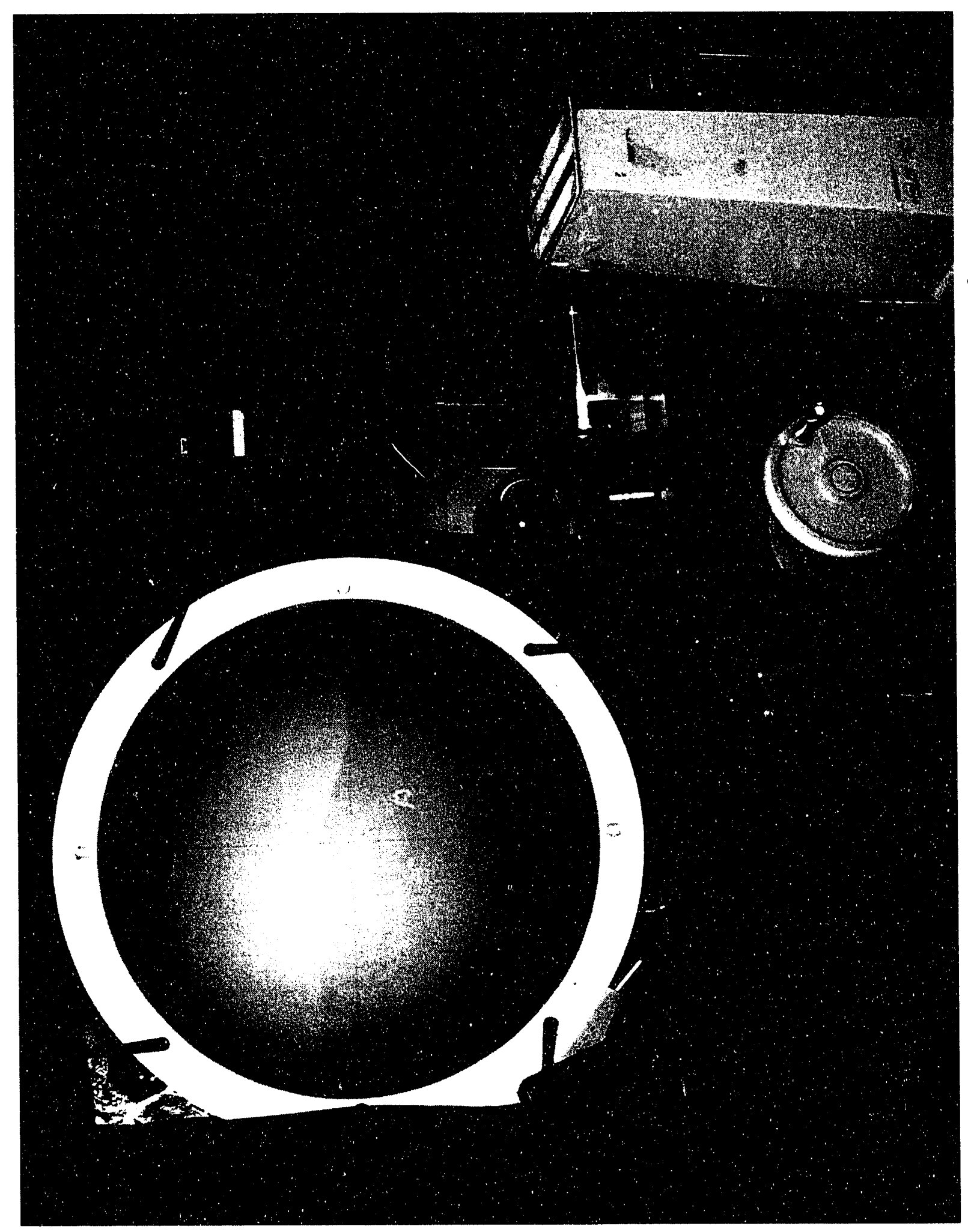

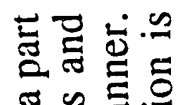

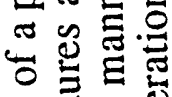

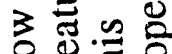
윤응 究氖.

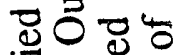
语气 해원음 蹋> 을 잉 통 引 10 舟

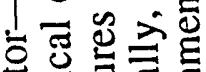

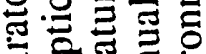
잉 흔

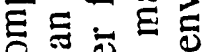
U它司 요응. .웡ㅇㅇㅇ 흥 क क

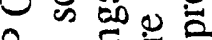

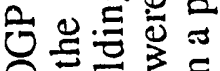
$0=5$ 을 异

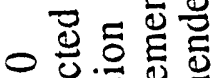
엉메 잉유

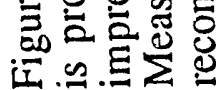




\section{DRA WINGS AND PHO TOS}

The drawings (figures 11 and 12) presented in this section were used to produce the two parts for which the manufacturing processes were developed. Both drawings are modifications of actual component drawings provided by the two participating contractors.

The photographs (figures 13 and 14) show the two components at successive stages of process development. 

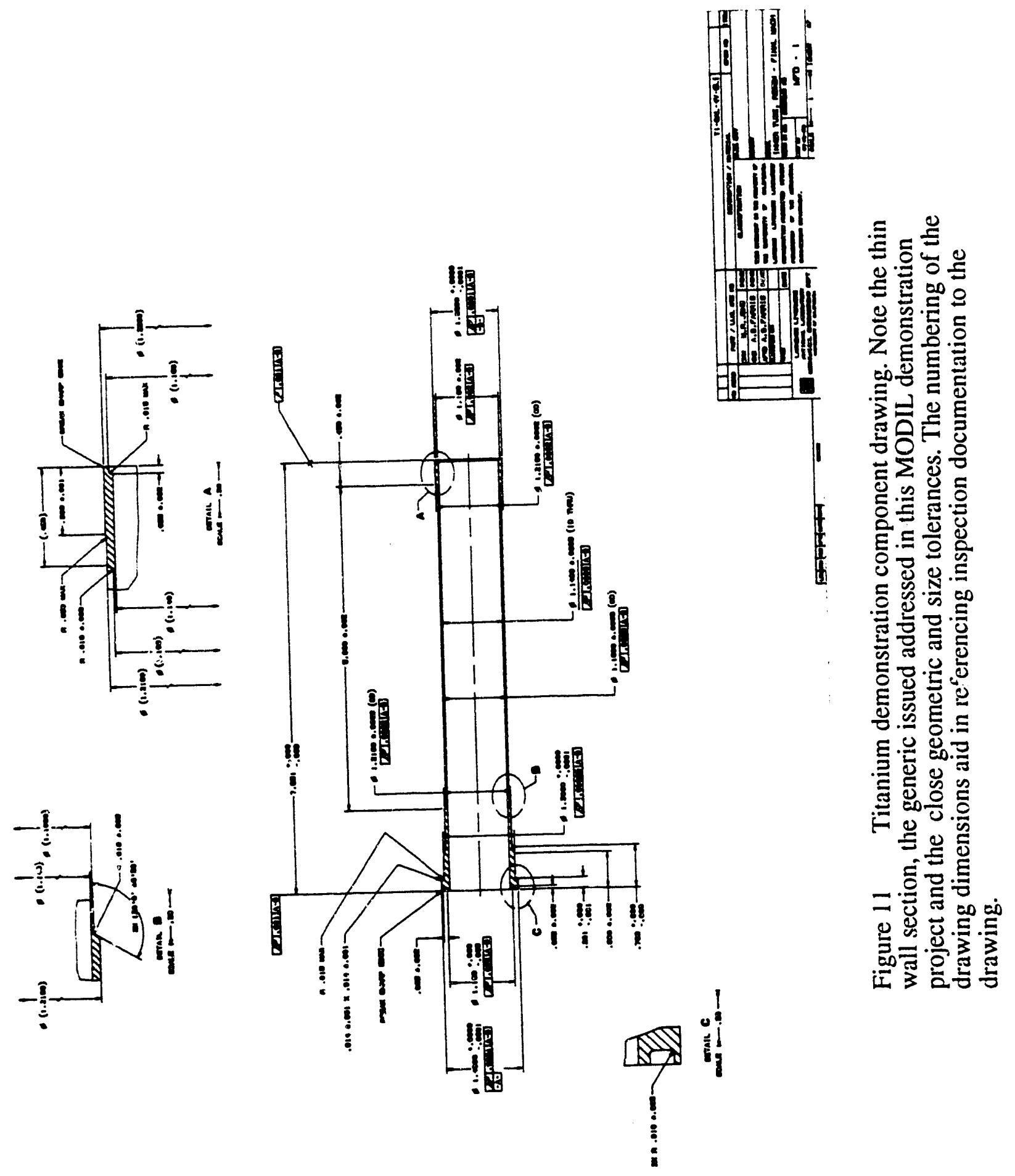

114

| ill!

in:

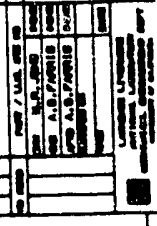

콩

政

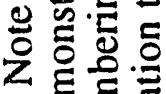

ผ0월 吾

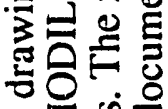

站

픈

․ㅗ웡

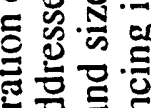

喝

氙导

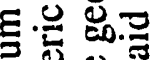

馬 哭응

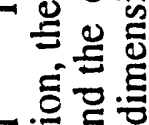

二

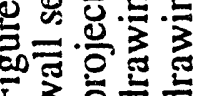



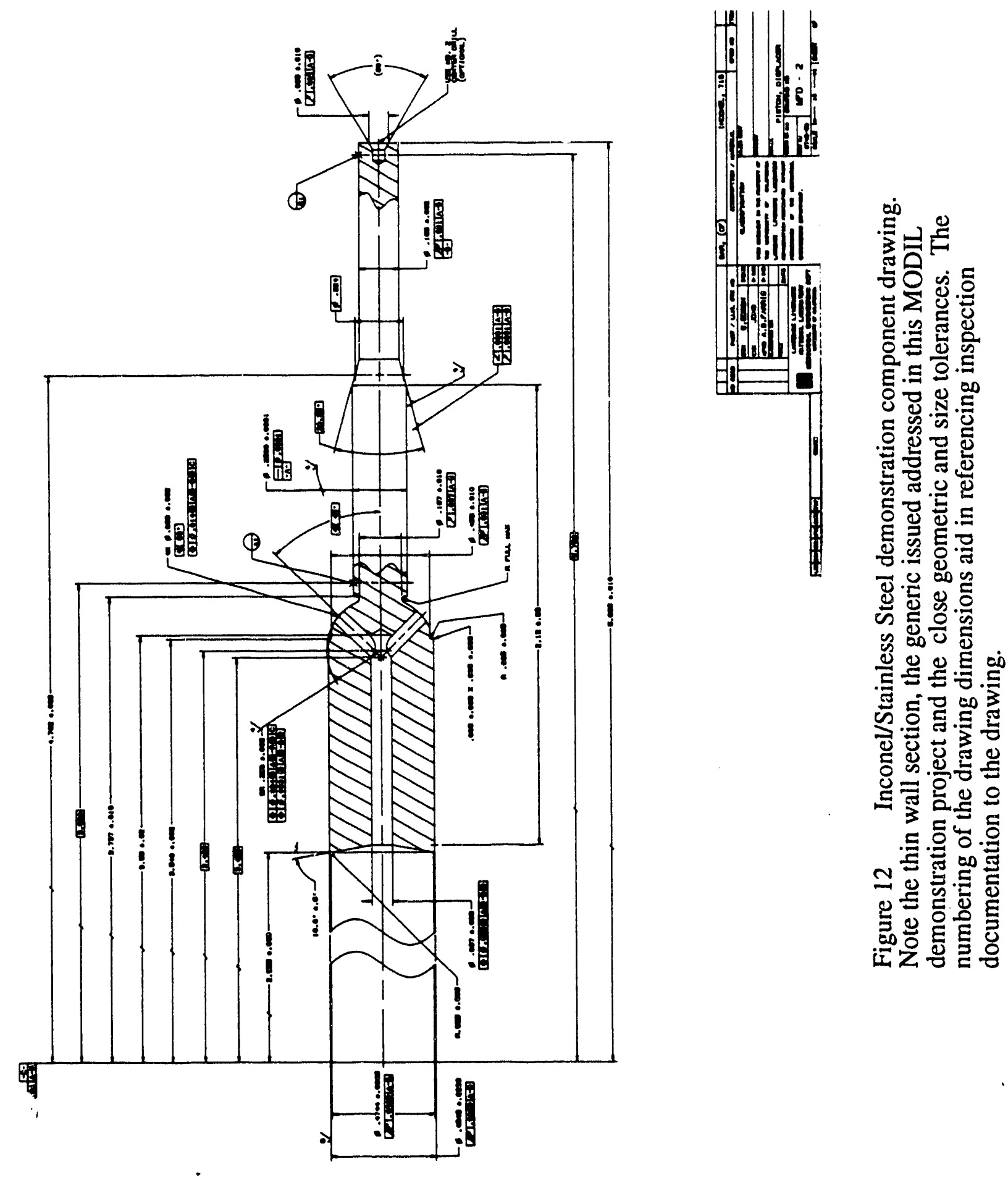


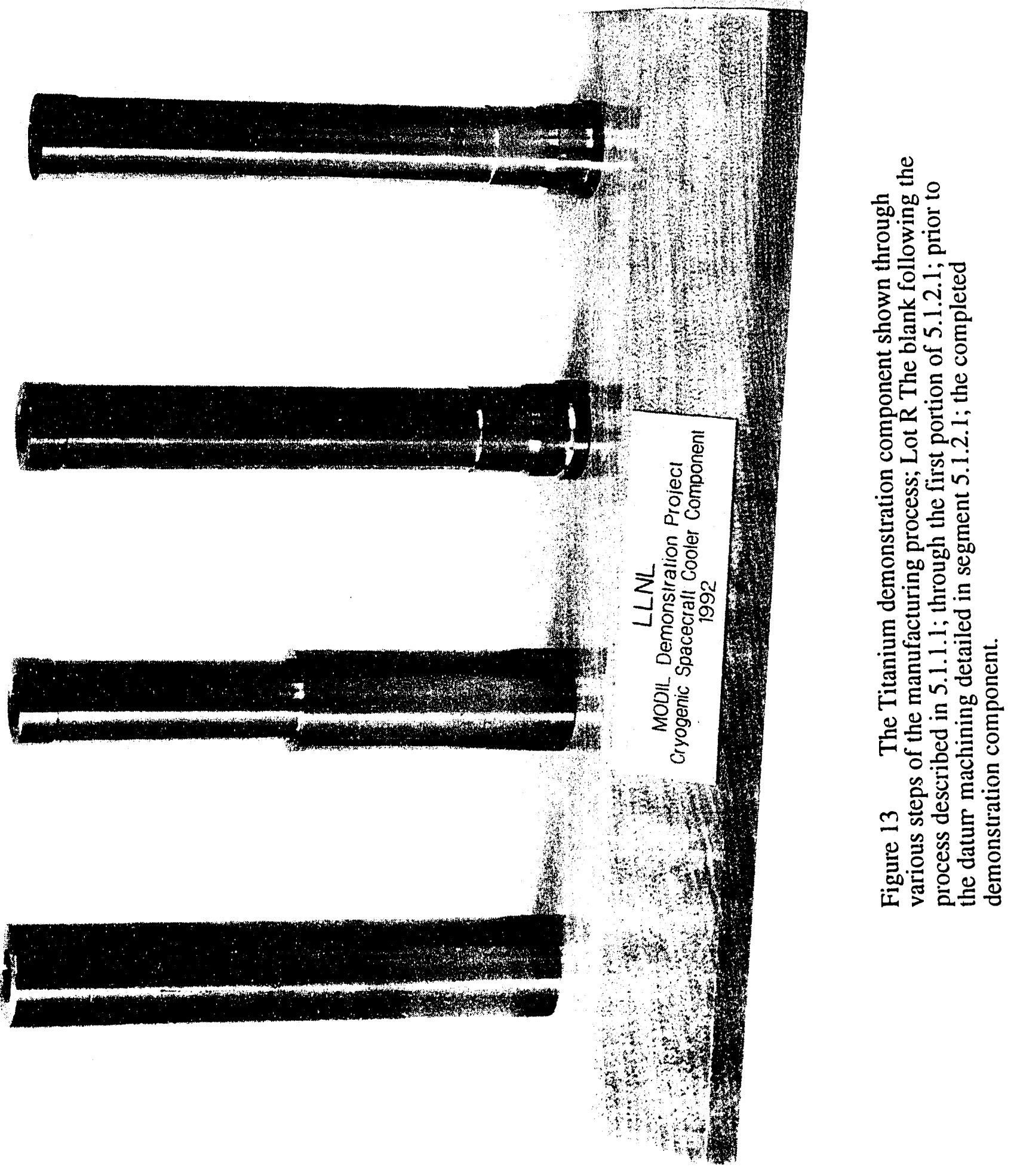




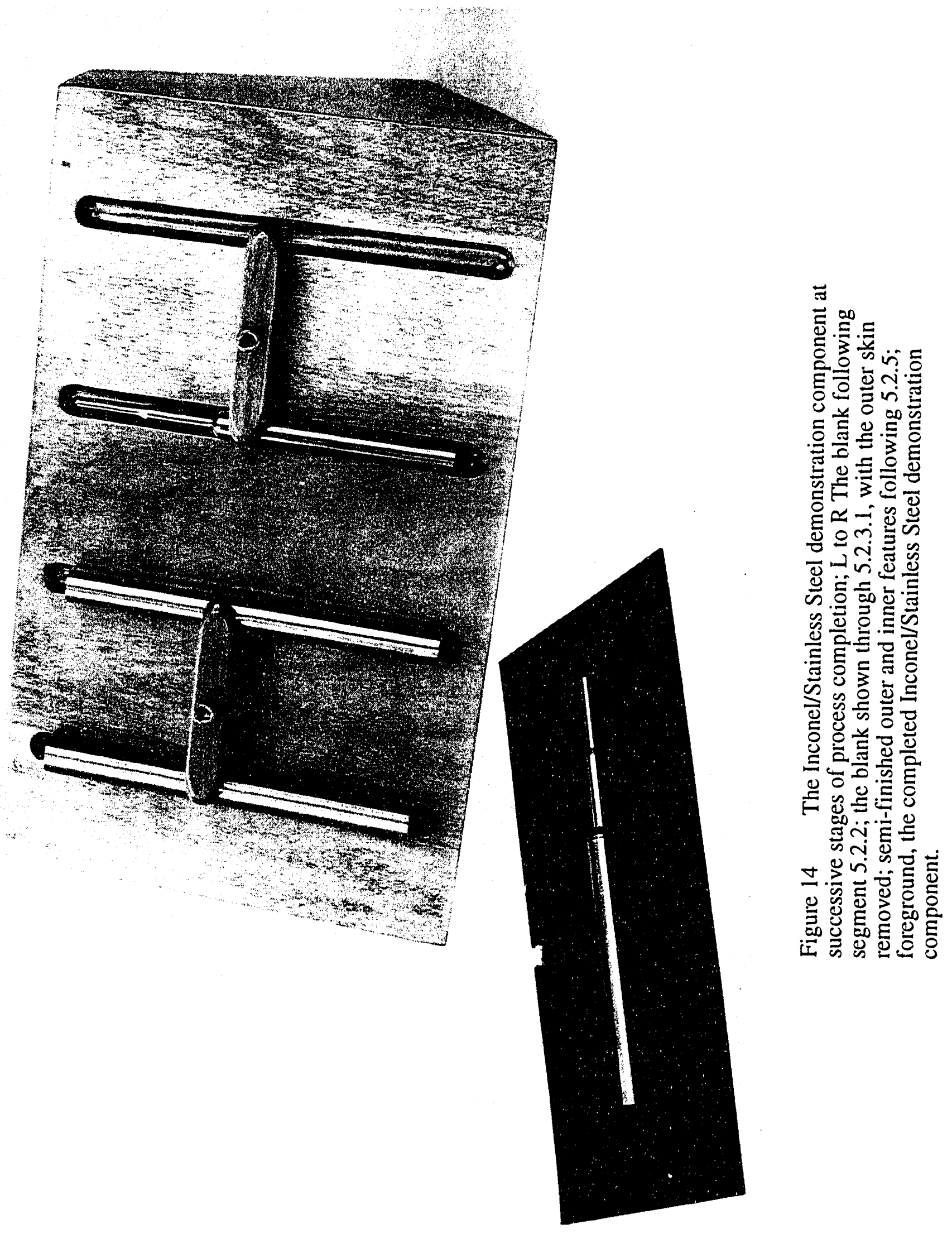




\section{MANUFACTURING DATA}

5.1

Titanium 6A14V

5.1.1

Blank Preparation

5.1.1.1

Process

Due to a compressed project schedule, we obtained one and one-half-inch diameter bar stock in four foot lengths foi the demonstration project. The blanks were sawed to length, leaving approximately one-eighth inch for face machining, bringing the initial facing operation blank length to .03 inch over the finish dimension. A one-inch diameter hole was then drilled through the center of the blank, creating a tube. These processes, though carried out on standard machine tools, are not optimum for a production environment; however, this method was employed for expediency.

\subsubsection{Recommendation}

Blanks should be purchased in a tuhular configuration to optimize the manufacture and reduce the cost of these components.

\subsubsection{Parameters}

\begin{tabular}{cccc}
\hline SFM Work Speed & IPR Feed Rate & Depth of Cut (inch) & Tool Designation \\
200 & .010 & .025 & KNGP-K313
\end{tabular}

Table 1: $\quad$ Parameters used for the Blank Facing Operations

\begin{tabular}{|cccc|}
\hline RPM Work Speed & IPR Feed Rate & IPT & Tool Designation \\
330 & .010 & .005 & Cobalt Steel \\
\hline
\end{tabular}

Table 2: $\quad$ Parameters used for the Blank Drilling Operation

\subsubsection{Rough Machining}

\subsubsection{Process}

The "as received" blank is machined to a semi-finished configuration to remove stock before annealing and finishing. Most numerically controlled lathes can be used to perform this operation. The blank was chucked with 4 inches protruding from the chuck jaw faces. A multi pass roughing operation was performed to leave .025 inch diametrical stock for finishing. The blank was then reversed in the chuck and supported on the 1.160 inch diameter section. A second roughing operation, using the same parameters, was performed. The over all length was left .02 inch longer than the finished component, leaving material for subsequent finishing operations.

Finish allowances are symmetrical, with equal amounts of stock removed from each end during the finishing operation. 


\subsubsection{Parameters}

\begin{tabular}{|cccc|}
\hline SFM Work Speed & IPR Feed Rate & Depth of Cut & Tool Designation \\
200 & .010 & .025 & KNGP-K313 \\
\hline
\end{tabular}

Table 3: Parameters for the Rough Machining Process

\subsubsection{Heat Treat Cycle}

\subsubsection{Metallographic Investigation}

An abbreviated metallographic study of the annealing and stabilization processes was conducted. Sample coupons were subjected to the various processes, sectioned and examined with a $500 \mathrm{X}$ microscope. The resulting micrographs (figures 15-18) reveal no appreciable differences in grain structure or hardness of the sample pieces. The annealing processes are detailed in the following sections of this report. An alternate vacuum annealing process (5.1.3.5) was requested by the contractor after this study was concluded. This alternate process was not included in the study.

\begin{tabular}{|c|c|}
\hline Sample Identification & Process \\
\hline $\mathrm{Al}$ & Vacuum anneal only (5.1.3.2) \\
\hline $\mathrm{Bl}$ & Cryogenic stabilization only (5.1.3.3) \\
\hline $\mathrm{Cl}$ & \begin{tabular}{c} 
(5.1.3.2 and 5.1.3.3) \\
\hline $\mathrm{DI}$
\end{tabular} \\
\hline
\end{tabular}

Table 4: $\quad$ Samples Identified to Corresponding Processes

Additional information regarding the EDM processing of these coupons is reported in section 5.1.5.4 of this report. 


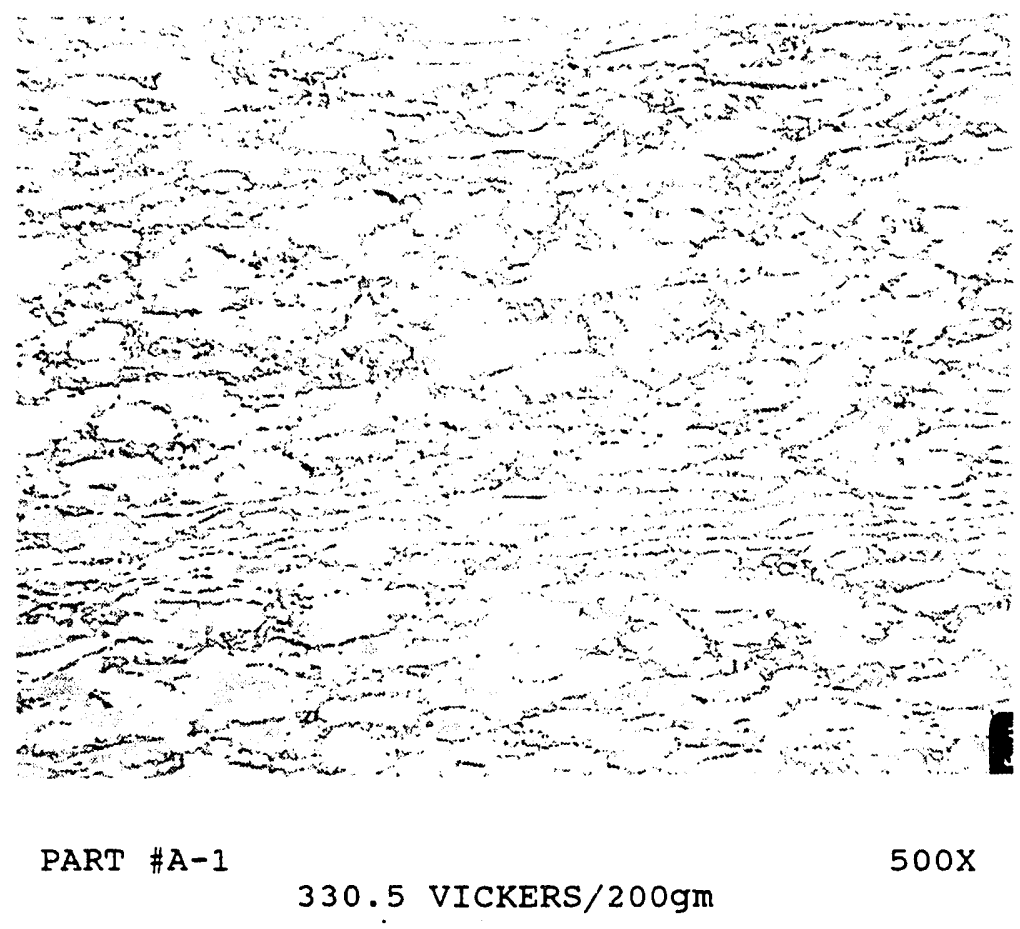

Figure 15 Part A-1-Vacuum Anneal Only

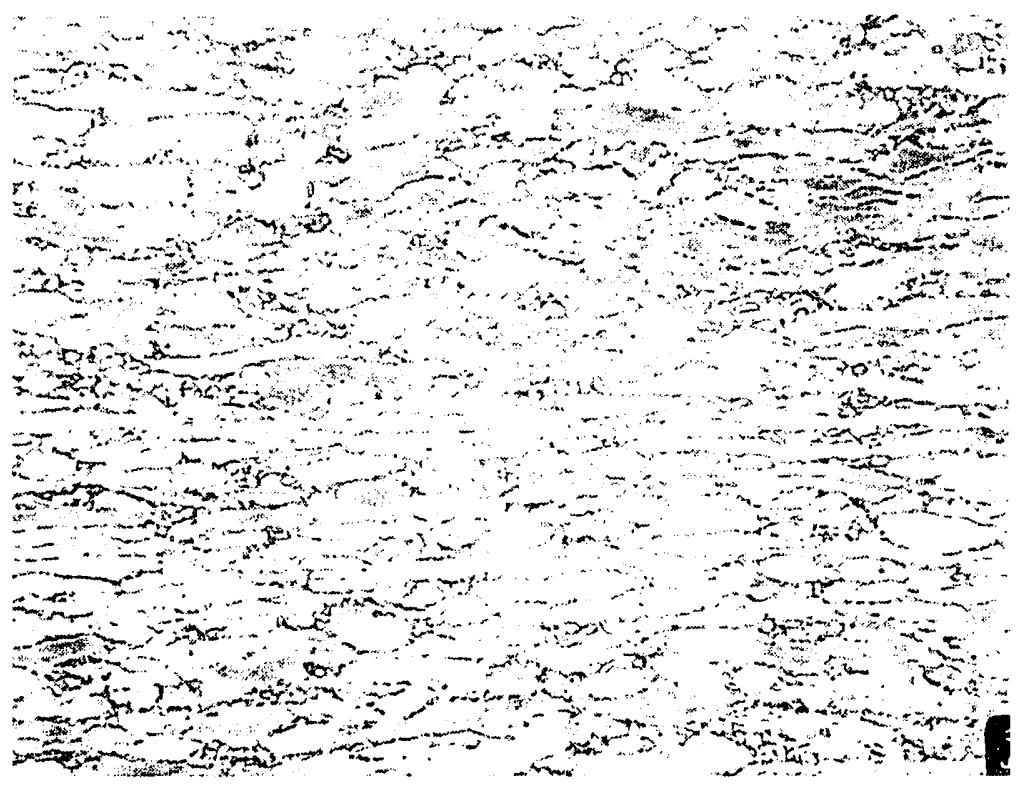

PART \#B-1

332.5 VICKERS/200gm

$500 x$

Figure 16 Part B-1-Cryogenic Stabilization Only 


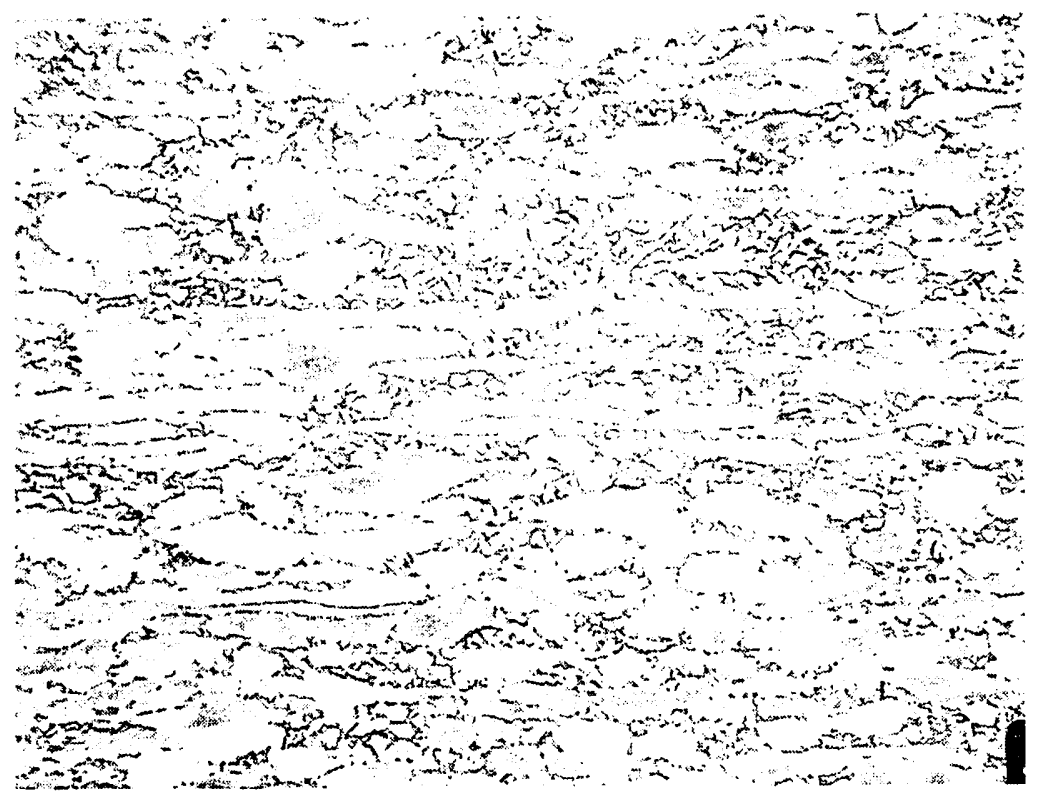

PART \#C-1

$500 x$

Figure 17 Part C-1-Vacuum Anneal and Cryogenic Stabilization

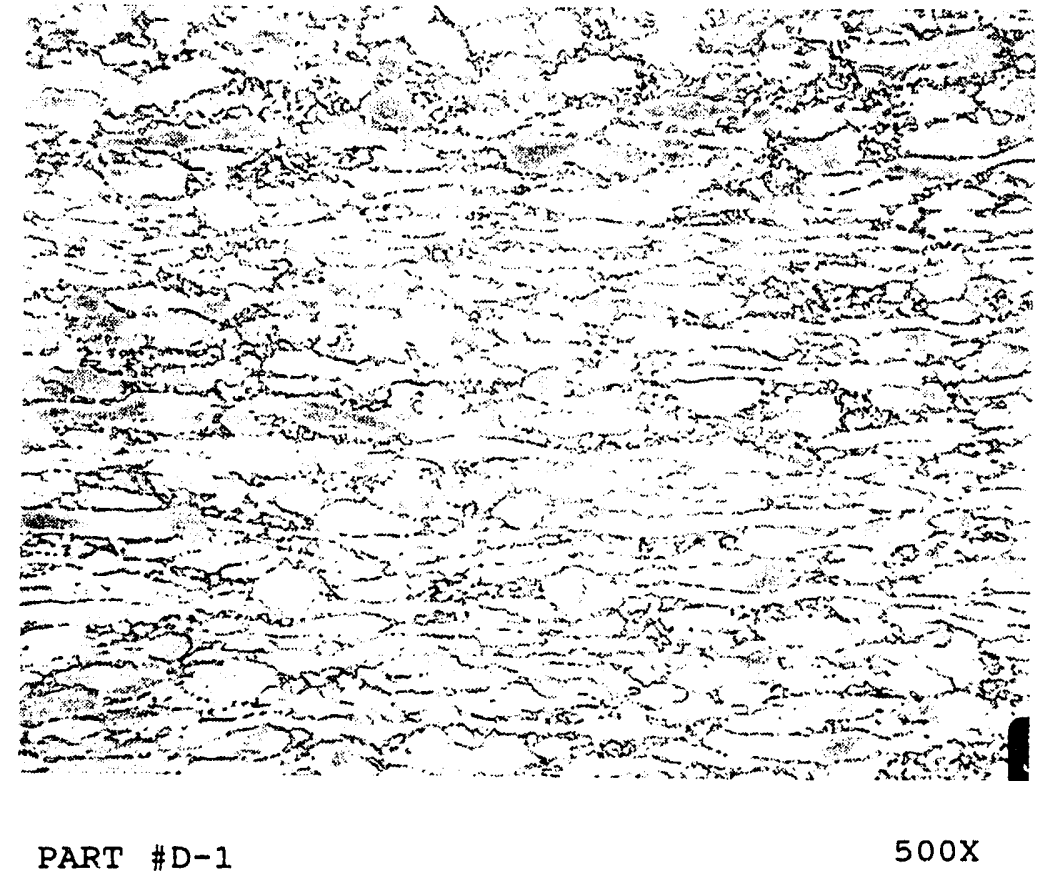

356.5 VICKERS/200gm

Figure $18 \quad$ Part D-1-Stock Material 


\subsubsection{Vacuum Anneal}

The blanks were annealed at 1300 degrees $F$ and held at temperature for two hours in an Abar BM-772 vacuum furnace. A temperature ramp speed of 60 degrees per minute was used with the furnace vacuum at $10^{-5}$ TORR. The blanks were allowed to return to room temperature by furnace cooling. This cooling takes approximately eight hours of the $121 / 2$ hour process (figure 19).

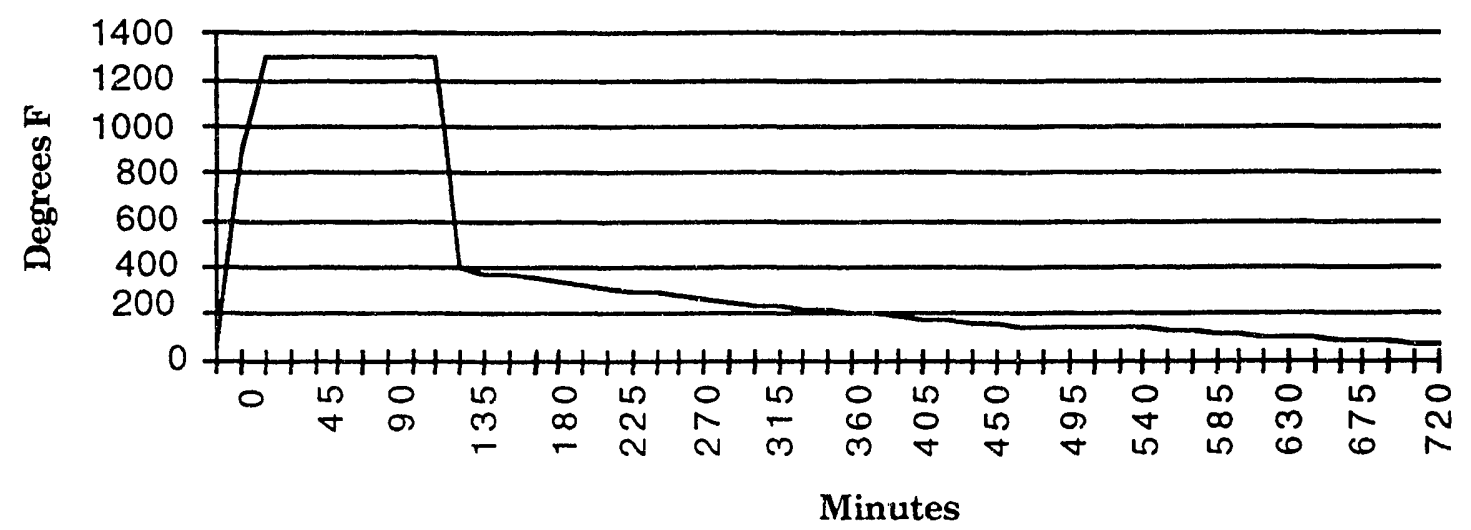

Figure 19 Titanium Component Vacuum Anneal Process

\subsubsection{Alternate Process Investigation-Cryogenic Stabilization}

The technology of cryogenic treatment of materials is not fully understood. We have used this process successfully on aluminum parts to provide greater material stability. Cryogenic cooling helps to maintain geometric tolerances such as flatness, parallelism and surface profile by minimizing stresses in the material. Cryogenic processing allows the material to retain mechanical properties that would otherwise be lost with the application of conventional heat treating processes.

Industry has used the cryogenic process for approximately ten years to extend the cutting life of steel and carbide cutting tools 2 .

Subsequent to the vacuum anneal process, a control sample of titanium blanks was processed following the cryogenic sequences shown in figure 20 . The applicability of this process and any resulting manufacturing benefits for this component were determined to be nil.

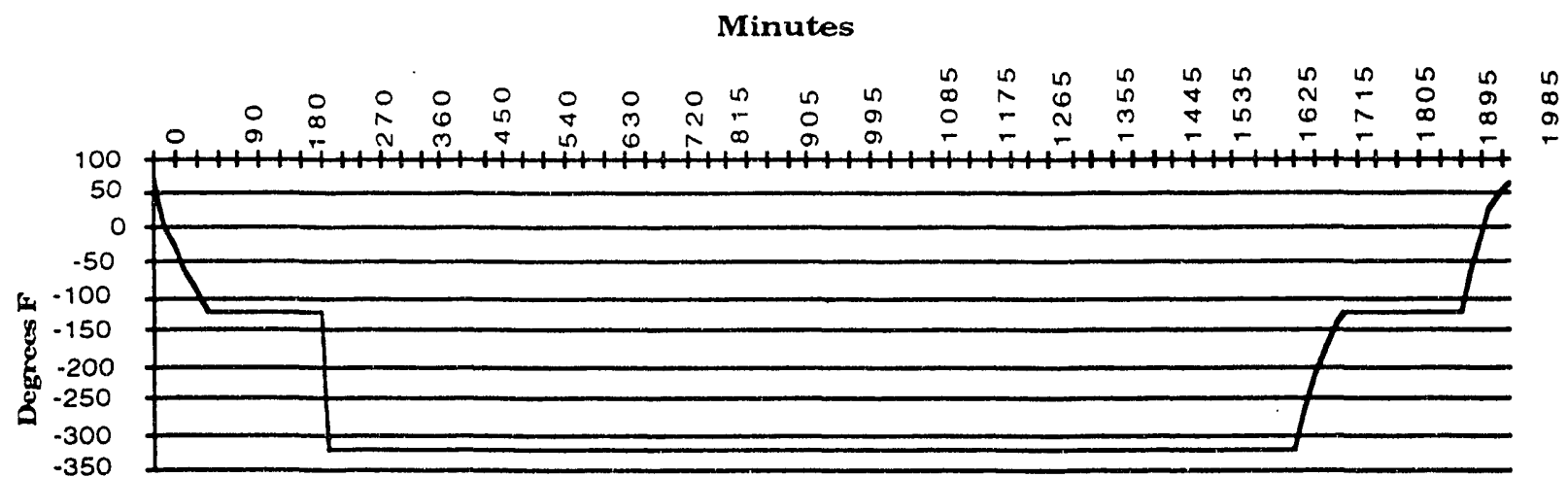

Figure 20 Titanium Component Cryogenic Stabilization Cycle 


\subsubsection{Recommendation}

This process did not result in a more stable work piece than blanks subjected to the lone vacuum anneal process. Benefit or detriment was not detected in the control batch; therefore, the cryogenic process is not necessary.

\subsubsection{Alternate Vacuum Anneal Process (Contractor supplied)}

The blank was vacuum annealed at 1350 degrees $F$ and held at temperature for four hours. A ramp speed of fifteen degrees per minute was used. Appreciable differences in geometric stability were not noted in the blanks subjected to this alternate process; however, a complete study may conclude differently (figure 21 ).

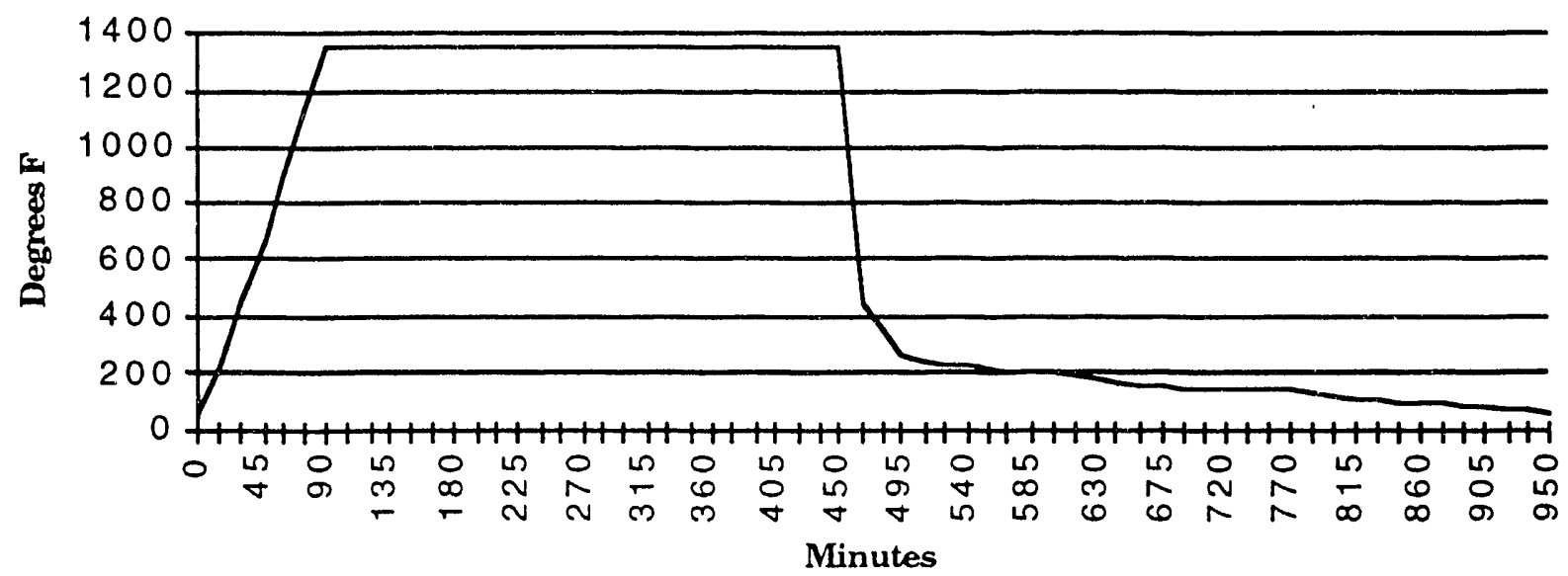

Figure 21 Titanium Component Alternate Vacuum Anneal Process

\subsubsection{Datum Machining}

This operation establishes diameters - A- and -B-, from which most subsequent features are referenced. Precise alignment of the blank is not critical at this point; however, stresses should be minimized in the clamping of the blank.

\subsubsection{Fixture}

The aluminum mandrel's outer diameter is about .010 inch smaller than the bore of the blank. A 3/8-24 threaded hole is machined into the end of the mandrel. This will accept the screw and washer unit used to hold the part on the mandrel.

The 3/8-24 screw was modified to accept a 60 degree live center from the tailstock for support and vibration dampening.

\subsubsection{Process}

The blank was placed on the mandrel, lightly secured with the screw, and indicated to within .002 inch maximum runout. The tailstock was then engaged to provide support and vibration dampening. Datum diameters - A- and - B- were then cut to .02 inch oversize. This .005 inch skim cut establishes the concentricity of these iwo diameters following the annealing process. Size will be attained in a subsequent operation. 
The weld prep grooves in both faces were initially machined at this stage. The groove designated by dimensions 9,21 , and 23 (figure 11) proved to have a negative effect on the flushing action in the wire EDM operation that finished the inner feature. The small groove defined by dimensions 5 and 30 (figure 11) should be completed at this stage of the process by using standard manufacturing practices.

\subsubsection{Recommendation}

It is suggested that the weld prep groove designated by dimensions 9,21 , and 23 (figure 12) be produced in the outer profile finishing sequence following the finishing of the inner feature.

\subsubsection{Parameters}

$\begin{array}{cccc}\text { SFM Work Speed } & \text { IPR Feed Rate } & \text { Depth of Cut } & \text { Tool Designation } \\ 200 & .(010 & .005 & \text { VC-29 }\end{array}$

Table 5: $\quad$ Datum Machining Parameters

\subsubsection{Electrical Discharge Machining (EDM) of Inner Feature}

\subsubsection{Process}

A wire EDM process was used to finish the inner feature. The part was mounted in the fixture with about .001 inch clearance between the clamping mechanism and the part. A stop was clamped to the bottom fixture plate to assist in vertical alignment. Eastman 910 adhesive was used to secure the blank in the fixture. A ground strap of aluminum tape was attached to the blank and to the machine ground. This assured conductivity requirements were met.

An Agietron Agiecut 200 (figure 4) and a Charmille Robofil 600 (figure 5), both capable of submerged cutting, were used in the development of this process. A series of four cuts was made to achieve size, finish and geometric feature. This "skim cutting" technology is commercially available and currently used in the EDM industry.

\subsubsection{Recommendation}

Most variables can have a major impact in a positive or negative manner on the close tolerances of size and geometry of these components. A primary variable, water conductivity, determines the consistency of the spark gap and should not exceed 20 micro-siemens for precision EDM operations.

The EDM machine tool should be operated in the mode presenting the finest resolution of machine table movement. The metric mode generally provides the finest resolution available on machine tools today. The metric mode was used on the EDM machine tools at LLNL during the development of this process.

A reduction in the environmental influences of the machine tool will result in greater accuracy and repeatability during the manufacturing process.

Isolation from ground vibration will enable the machine tool to produce a more consistent feature. Vibration dampening pads, supplied with the machine tool, should be used as a minimum precaution. Additional isolation can be achieved by anchoring the machine tool to a stable foundation.

Thermal variations can cause the physical features of the machine tool to drift. Three such thermal influences are; an air conditioner or heater blowing on the tool, and opening an outside door near the machine tool. The machine tool can be protected from these sudden thermal shocks 
by physically shielding it from these direct sources of temperature change. Protection can be in the form of an enclosure that can be designed to provide temperature, particulate, and humidity controls.

\subsubsection{Parameters}

A $0.25 \mathrm{~mm}$ diameter Gisco brand, Bronco Cut $\mathrm{X}$ wire was used in the development of cutting parameters.

\section{Power and Wire Settings}

\begin{tabular}{|c|c|c|c|c|}
\hline & Main Cut & First Trim & Second Trim & Third Trim \\
\cline { 2 - 5 } M & 5 & 5 & 5 & 2 \\
$\mathrm{t}$ & 12 & 8 & 8 & 20 \\
$\mathrm{I}$ & 10 & 10 & 4 & 5 \\
PR & 10 & 1 & 1 & 1 \\
P & 10 & 32 & 32 & 32 \\
td & 25 & 35 & 40 & 32.5 \\
HC & 10 & 1 & 1 & 0 \\
CW & 2 & 2 & 2 & 2 \\
FW & 20 & 20 & 20 & 20 \\
VW & 180 & 160 & 140 & 140 \\
\hline
\end{tabular}

Table 6: $\quad$ Power and Wire Settings for the Agietron 200

M: Establishes the "mode" that the machine works in

$\mathrm{t}$ : $\quad$ Preselection for the pulse duration, varies according to $\mathrm{M}$

I: $\quad$ Selection of maximum pulse current amplitude

PR: $\quad$ Power range, adapted to a selected power level

P: $\quad$ Selector switch for maximum power erosion

$t_{d}: \quad$ Discharge delay preselection

HC: Height compensation for workpiece dependent bowing-back of wire in full thickness cut

Cw: Class of wire (two is for wires above $.1 \mathrm{~mm}$ diameter)

Fw: Tension of wire in the work zone in Newtons

Vw: Rate of unwinding for the wire electrode

\section{Flushing Settings}

\begin{tabular}{|c|c|c|c|c|}
\hline & Main Cut & First Trim & Second Trim & Third Trim \\
\cline { 2 - 5 } B & 1 & 1 & 1 & 1 \\
K & 10 & 10 & 10 & 10 \\
Q & 3 & 1 & 1 & 1 \\
Qo & 12 & 12 & 12 & 12 \\
Qu & 12 & 12 & 12 & 12 \\
Qou & .4 & .4 & .4 & .4 \\
\hline
\end{tabular}

Table 7: $\quad$ Flushing Parameters for the Agietron 200

B: $\quad$ Selection parameters for eroding in a bath (submerged work piece)

$\mathrm{K}$ : Water conductivity in micro-siemens/centimeter

Q: $\quad$ Selection of programmed flushing parameters

Qo: $\quad$ Full thickness cut in plane/parallel parts

Qu: $\quad$ Full thickness cuts in parts with recesses

Qou: First full thickness cut, follow up cut 


\section{Geometric Setting}

\begin{tabular}{|c|c|c|c|c|}
\hline \multirow{2}{*}{$\mathrm{D}$} & Main Cut & First Trim & Second Trim & Third Trim \\
\cline { 2 - 5 } & .257 & .191 & .174 & .169 \\
\hline
\end{tabular}

Table 8: $\quad$ Geometric Parameter Setting for the Agietron 200

D: The offset distance, expressed in millimeters, for determining the size of the feature. This value is a function of the finished dimension, power, flushing, and wire size parameters.

\subsubsection{Metallographic Investigation}

Cursory studies were conducted to quantify the heat affected zone and to determine the integrity of the EDM surface. The heat affected zone was determined to be $.0005 \mathrm{inch}$, measuring from the largest "nodule" to the base of the modified grain structure of the material (figure 22-25).

An attempt to determine the adhesion characteristics of the "nodules" was conducted by applying a .75 inch $^{2}$ tape to the EDM surface. Removal of this tape was followed by a $150 \mathrm{X}$ microscopic video examination for particulate. A "soot" was found on the tape in several places, but no distinguishable particulate was discovered. 


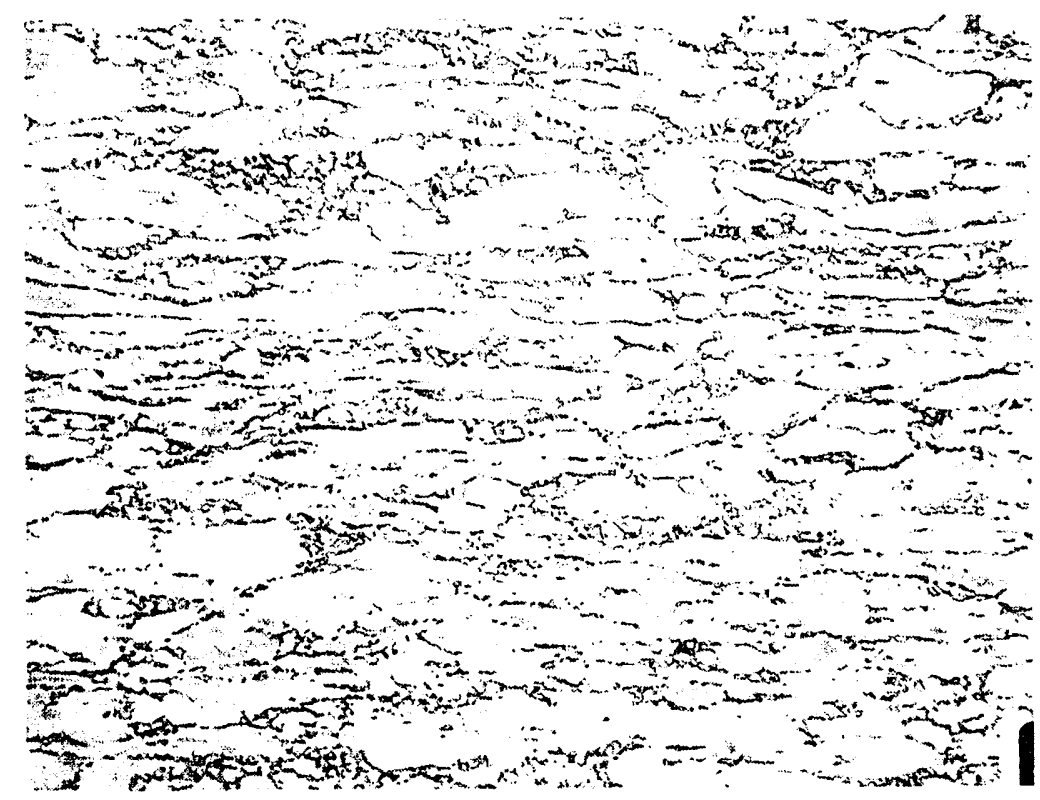

PART \#A-2

304.5 VICKERS/200gm

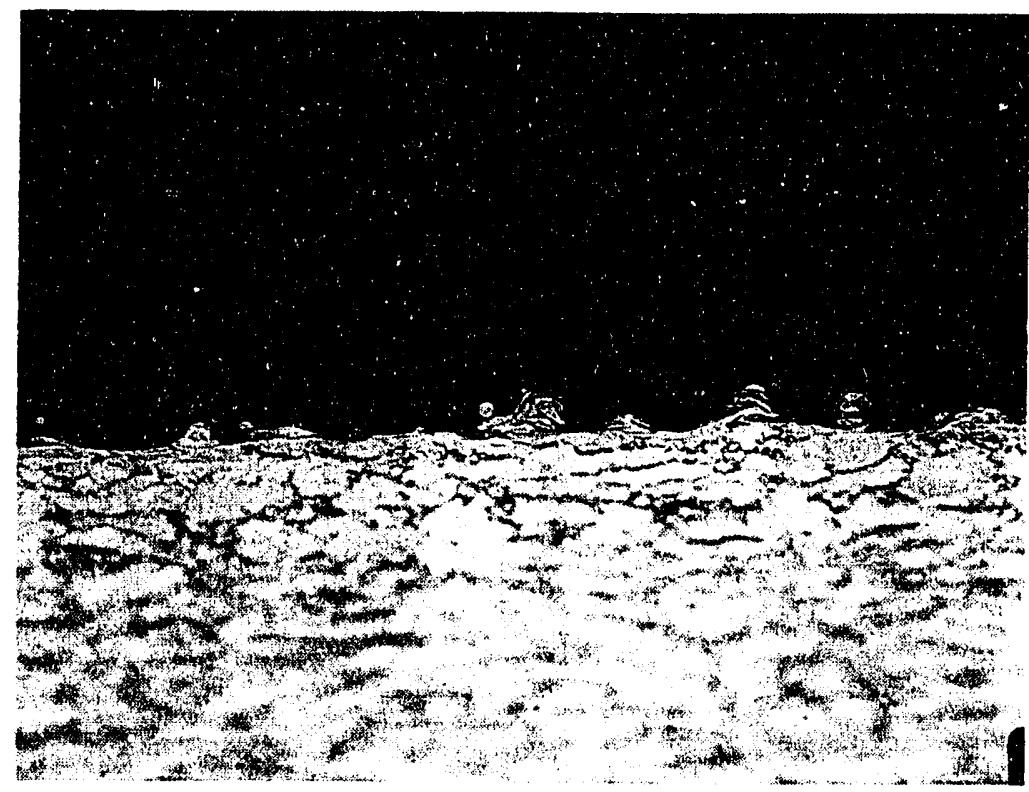

PART \#A-2

EDM CUT SURFACE

Figure 22 Part A-2-Vacuum Anneal and Wire EDM. Top: A 500 times magnification of the grain structure of $6 \mathrm{Al} 4 \mathrm{~V}$ Titanium (ELI variety) after undergoing the vacuum anneal process followed by EDM processing. Material hardness, based on the Vickers scale is shown. Bottom: A sectional view of the EDM surface, note the nodules that have attached themselves to the surface and the compressed grain structure near the surface. Determination of the .0005 inch heat affected zone was made from this photomicrograph. 

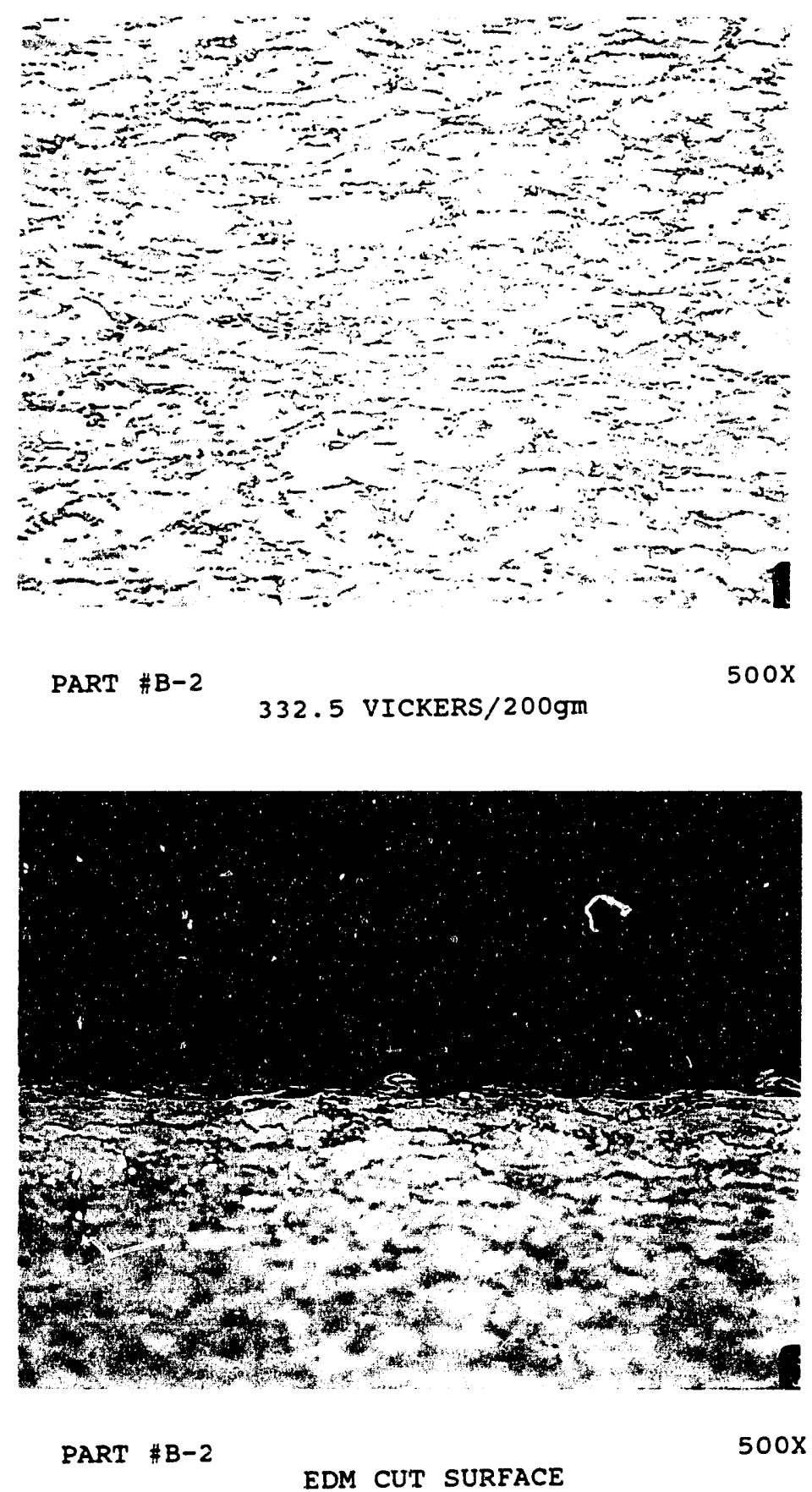

Figure 23 Part B-2-Cryogenic Stabilization and Wire EDM. Top: A 500 times magnification of the grain strucure of $6 \mathrm{Al} 4 \mathrm{~V}$ Titanium (ELI variety) after undergoing the cryogenic stabilization process followed by EDM processing. Material hardness, based on the Vickers scale is shown. Bottum: A sectional view of the EDM surface, note the nodules that have attached themselves to the surface and the compressed grain structure near the surface. This is the heat effected zone generated by the, EDM process. 


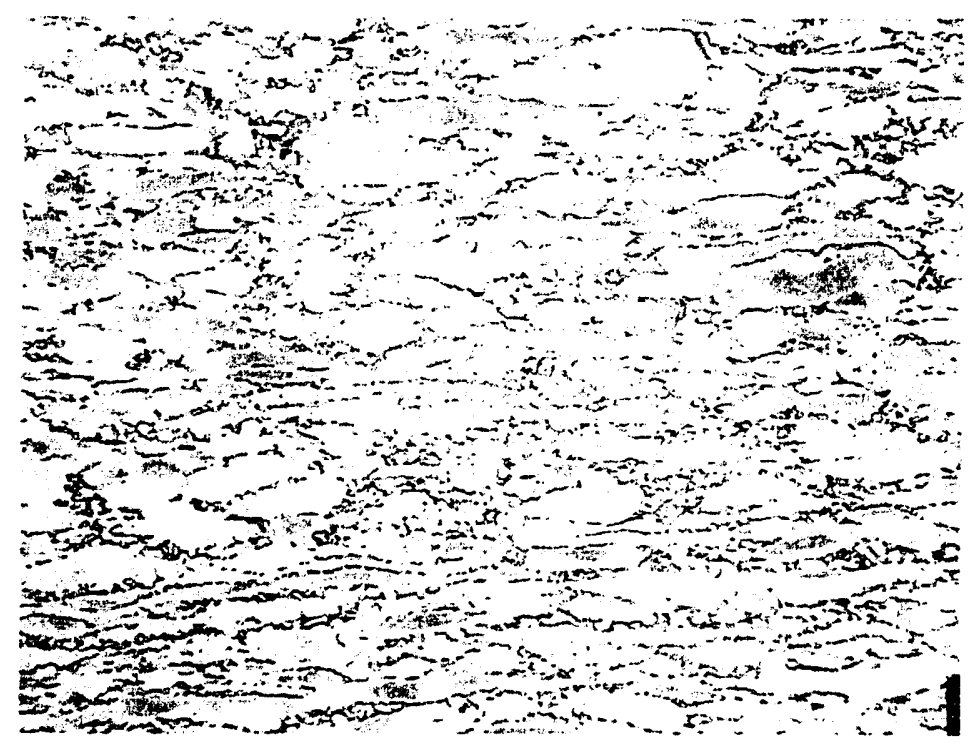

PART \#C-2

$500 x$

299.3 VICKERS/200gm

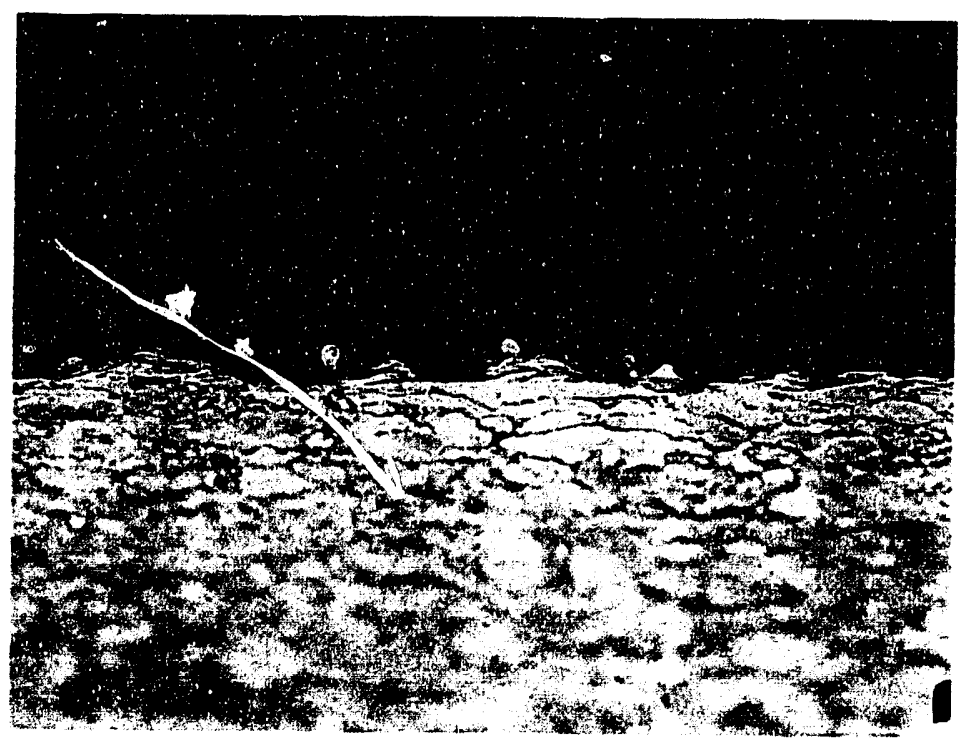

PART \#C-2

$500 x$

EDM CUT SURFACE

Figure 24 Part C-2-Vacuum Anneal followed by Cryogenic Stabilization and Wire EDM. Top: A 500 times magnification of the grain structure of $6 \mathrm{Al} 4$ $V$ Titanium ELI after undergoing the vacuum anneal process and cryogenic stabilization, followed by EDM processing. Material hardness, based on the Vickers scale is shown. Bottom: A sectional view of the EDM surface, note the nodules that have attached themselves to the surface and the compressed grain structure near the surface. This is the heat eflected zone generated by the EDM process. 


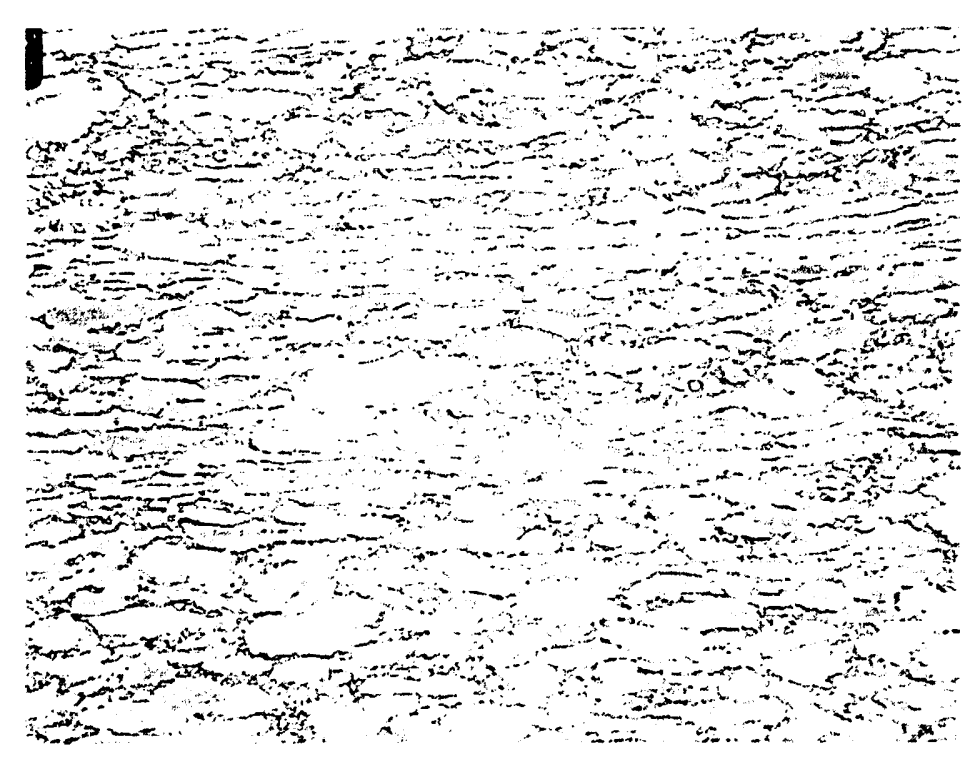

PART \#D-2

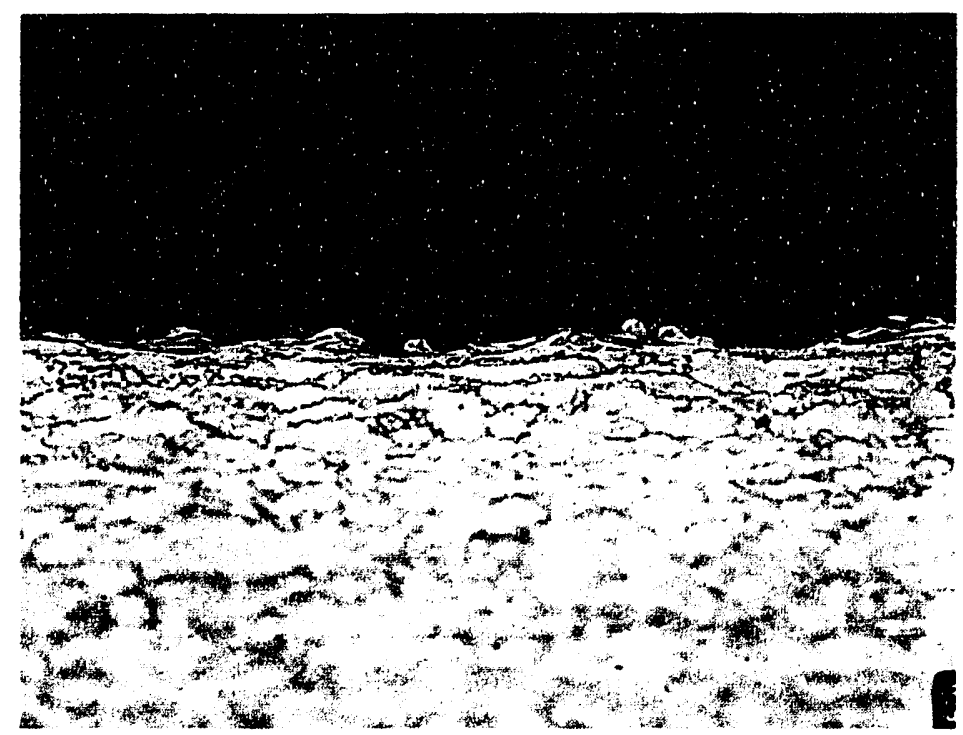

PART \#D-2

$500 x$

EDM CUT SURFACE

Figure 25 Part D-2-Stock Material and Wire EDM. Top: A 500 times magnification of the grain structure of $6 \mathrm{Al} 4 \mathrm{~V}$ Titanium (ELI variety) stock. Thermal processing was not done prior to EDM processing. Material hardness, based on the Vickers scale is shown. Bottom: A sectional view of the EDM surface, note the nodules that have attached themselves to the surface and the compressed grain structure near the surface. This is the heat effected zone generated by the EDM process. 


\subsubsection{Recommendation}

Wire brushing of the EDM surface will remove most of the "soot". An acceptable material for the brush will need to be determined by the cryocooler supplier, and an acceptable cleaning procedure must be identified.

A complete metallurgical study of the effects of the EDM process should be undertaken to establish the process viability for cryocooler components.

\subsubsection{Finishing of Outer Features}

\subsubsection{Process}

The blank is mounted on a non-influencing mandrel. The mandrel diameter is cut .005 under the inner diameter of the blank to assure a free-state condition. Tail stock force is applied through the part to drive the blank. This driving method and mandrel configuration assure roundness and straightness within machine tool capability. Wall thickness and the related concentricity are compromised with this method.

\subsubsection{Alternate Process (Contractor supplied)}

This process will provide for a constant component wall thickness. It has a negative impact on the free state geometric requirements specified on the print. The mandrel, .0002 to .0003 inch over the nominal blank inner diameter, is placed in a deep freeze at -120 degrees $F$ for 12 hours. The blank and mandrel are assembled, allowed to return to room temperature and are then ready for the finish machining operation. This "shrink" fit provides for a constant wall thickness. Inner diameter irregularities will be transferred to the outer profile, resulting in a compromise of the free state geometric requirements.

\subsubsection{Recommendation}

Modification of drawing specifications to reflect the functional preference of a constant wall versus the free state geometric definition currently specified (figure 11).

\subsubsection{Parameters}

$\begin{array}{cccc}\begin{array}{c}\text { SFM Work Speed } \\ 200\end{array} & \text { IPR Feed Rate } & \text { Depth of Cut } & \text { Tool Designation } \\ & .010 & .005 & \text { VC-29 }\end{array}$

Table 9: $\quad$ Parameters for Finishing of the Outer Profile

\subsubsection{Inspection}

\subsubsection{Diametrical Size}

A laser micrometer was used to characterize external features. Air gaging was shown as a viable option for internal size determination. Conventional micrometers can be used to measure the more robust features.

\subsubsection{Runout Measurement Process}

Portions of the following sequence can be visualized by referring to figure 6 .

The Indi-Ron roundness gage was used to check the runout condition of the component. A small diameter, .001 inch, stylus probe tip is recommended to minimize the effects of airborne contaminates. 
Polar charts (figure 26) were generated for all diameters with a runout tolerance. All total runout requirements will need polar charts generated at one-half inch increments. When the cylinder is less than one half inch long, a chart at the top and bottom of the cylinder is required.

The component was placed, -A-datum end down, on the table of the Indi-Ron Gage and centered, it was then bonded in position with a cyanoacrylate adhesive.

The EDM "blue line" was oriented to zero on the polar chart. This "blue line" results from the initial EDM cut and provides a permanent index mark for future rotational reference to the documentation.

Align datums - A- and -B-; generate a polar chart to document concentricity.

A polar chart of the upper most face (datum B end) was generated to document the face runout.

The interior diameter was probed for runout using a four inch long probe. Runout measurements at one-half inch increments, were taken off of the inner surface and plotted on polar charts.

Datums - A- and -B- were reinspected to verify that their positioning had remained constant through this process. A polar chart was generated to document their position.

Straightness checks were made to tie the polar chart data together. This was done on a Federal Surfanalyzer (figure 9).

All charts must be clearly and completely marked with information relating to part serial number, location of measurement and leature heing measured. 


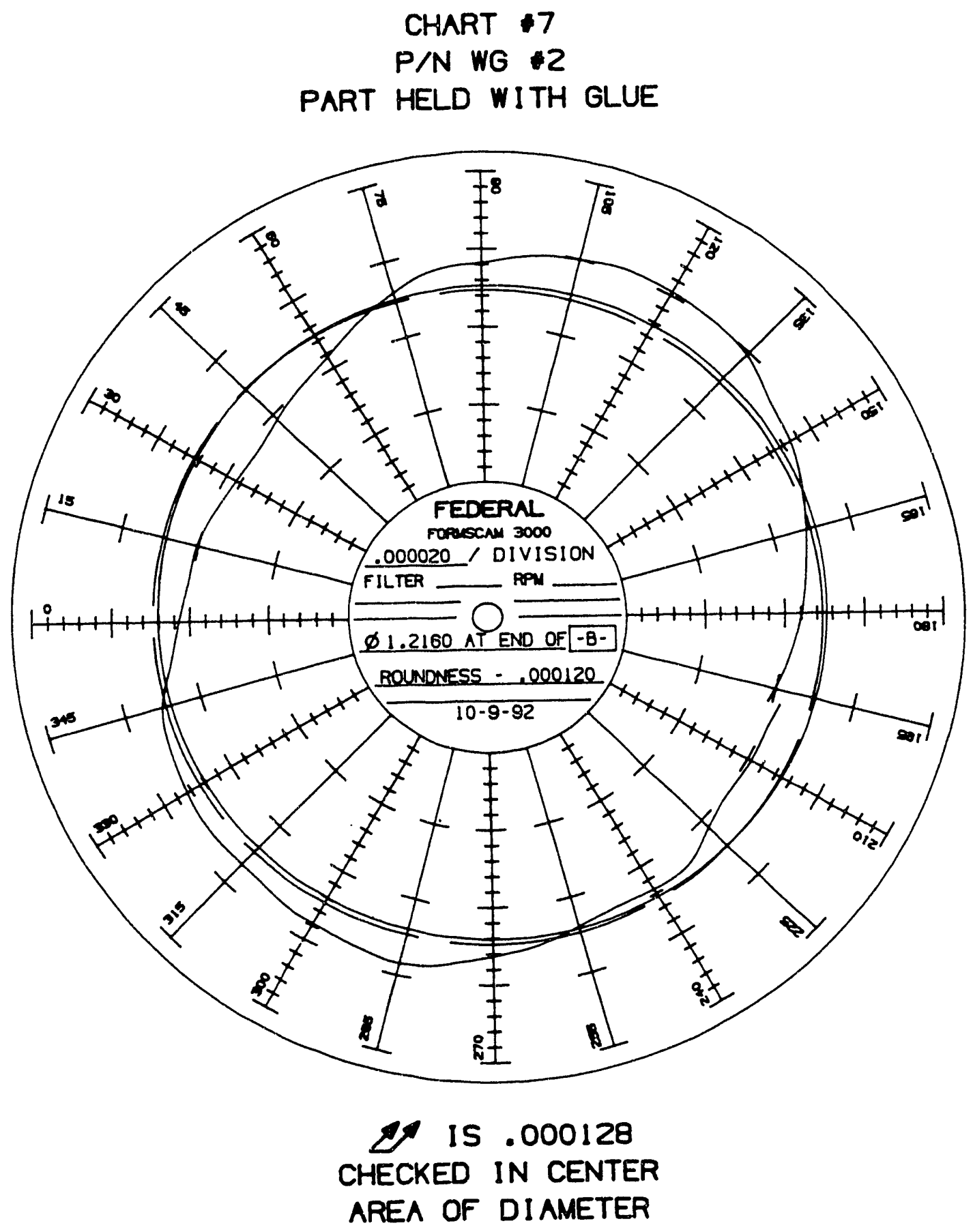

Figure 26 Polar Chart 


\subsubsection{Linear Features}

All external linear, angular, and radii features were measured and recorded with an optical comparator.

Internal radii and angles were transferred to an optical comparator and was then used to check these features.

Depth dimensions can be checked with a conventional depth micrometer.

Widths of grooves can be verified with gage pins or vernier calipers. 
Initial considerations led to the specification of 718 Inconel for this demonstration component. After a thorough attempt (see section 6), efforts were redirected to a vendor accepted alternative, 321 Stainless Steel. Manufacturing processes were similar for the two materials and are reported in this manner where possible. Alternative process investigations are also documented.

The understanding that all decisions, from process steps and machining parameters to equipment and personnel selection, have a major impact on the successful production of these components is one of the primary findings of this project. Maximizing speeds, feeds and depths of cut, standard practice in conventional manufacturing plans, is false economy when components of this nature are to be produced. Seemingly inconsequential operations, such as rough drilling the bore, are thought to have been a root cause of geometric instability encountered in our first attempts to produce this component.

\subsubsection{Recommendation}

Skilled crafts' people must be involved in the manufacture of these challenging parts. The team concept, bringing together manufacturing and inspection, proved valuable during the development of the following processes. We believe that this type of involvement would have been most beneficial beginning with the initial design phase, resulting in a more producible product. The development of a manufacturing plan, the "fine tuning" of it and strict adherence to it, will contribute greatly in the successful production of difficult components.

Most CNC lathes are capable of pertorming these operations, and are indeed encouraged, as they can provide the consistent culting conditions that help maintain the process control.

\subsubsection{Blank Preparation}

We obtained 5/8 inch diameter 718 Inconel and 321 Stainless Steel bar stock, in four foot lengths, for these demonstration parts. The blanks were sawed to length, leaving approximately $1 / 8$ inch for the initial face machining, which leaves the blank length .02 inch over the finish dimension.

\subsubsection{First Roughing Operation (Inconel/Stainless Steel)}

\subsubsection{Process}

The first operation removed the bulk of the inner material by drilling. The removal of the "skin" from one end of the blank's outer diameter was also done at this time. The removal of this skin relieves the stresses inherent in raw stock. These stresses are the result of the proper bar sizing and surface cooling contractions during manufacture.

The blank was gripped in a collet with three inches of material protruding for this operation. The blank was center drilled, then drilled with a .453 inch diameter cobalt drill to a depth to 2.5 inches. The outer diameter was turned to .578 inches with .01 inch depth of cuts. The light cuts were taken to minimize the introduction of stress into the blank. A Cool-Mist atomizer was used to apply a Trim--Sol mist to help keep the cutting tool and blank cool. Refer to Section 3.2 ior clarification on the use of Trim-Sol. 


\begin{tabular}{|cccc|}
\hline SFM Work Speed & IPR Feed Rate & Depth of Cut (inch) & Tool Designation \\
120 &.$(0)$ & .01 & VNMS 331 K-68 \\
\hline
\end{tabular}

Table 10: Parameters for the First Roughing Operation-718 Inconel

\begin{tabular}{cccc}
\hline RPM Work Speed & IPR Feed Rate & IPT (drill) & Tool Designation \\
280 & .010 & .005 & $.453 "$ Cobalt Steel \\
\hline
\end{tabular}

Table 11: Drilling Parameters for 718 Inconel Roughing Operation

\begin{tabular}{|cccc|}
\hline SFM Work Speed & IPR Feed Rate & Depth of Cut (inch) & Tool Designation \\
160 & .005 & .01 & VC-29 Hi-Rake* \\
\hline
\end{tabular}

Table 12: $\quad$ Parameters for the First Roughing Operation-321 Stainless Steel

* VC-29 grade carbide in 35 degree configuration with a .01 inch nose radius. An after market, 30 degree positive back rake was ground onto this insert to reduce cutting pressure.

\begin{tabular}{|cccc|}
\hline RPM Work Speed & IPR Feed Rate & IPT (drill) & Tool Designation \\
370 & .010 & .005 & .453 " Cobalt Steel \\
\hline
\end{tabular}

Table 13: Drilling Parameters for the 321 Stainless Steel Roughing Operation

\subsubsection{Second Roughing Operation (Inconel/Stainless Steel)}

\subsubsection{Process}

The blank was reversed and held in a $37 / 64$ inch collet, with a minimum of material protruding, for the roughing of the remaining diametric features and the spherical radius. Multiple passes were taken to remove stock and leave .02 inch on the .250 and .185 inch diameters, spherical radius and length. A flood coolant of Trim-Sol was used during this process to help remove heat from the cutting zone.

\subsubsection{Parameters}

\begin{tabular}{|llll|}
\hline SFM Work Speed & IPR Feed Rate & Depth of Cut & Tool Designation \\
120 & .01 & .02 & VNMS 331 K-68 \\
\hline
\end{tabular}

Table 14: Second Roughing Operation Parameters on the 718 Inconel Component

\begin{tabular}{|llll|}
\hline SFM Work Speed & IPR Feed Rate & Depth of Cut & Tool Designation \\
160 & .01 & .02 & VC-29 Hi-Rake* \\
\hline
\end{tabular}

Table 15: Second Roughing Operation Parameters on the 321 Stainless Steel

* VC-29 grade carbide in 35 degree configuration with a .01 inch nose radius. An after market, 30 degree positive hack rake was ground onto this insert to reduce cutting pressure.

\subsubsection{Heat Treat Cycle}

Conventional annealing processes and cryogenic stabilization processes were employed on the demonstration project components following the second roughing operation. 
The technology of cryogenic treatment of materials is not fully understood. We have used this process successfully on aluminum parts to provide greater material stability. Cryogenic cooling helps to maintain geometric tolerances such as flatness, parallelism and surface profile by minimizing stresses in the material. Cryogenic processing allows the material to retain mechanical properties that would otherwise be lost with the application of conventional heat treating processes.

Industry has used the cryogenic process for approximately ten years to extend the cutting life of steel and carbide cutting tools 2 .

\subsubsection{Stainless Steel - Vacuum Anneal}

Conventional annealing (figure 27) was performed on the Stainless Steel components following the second roughing operation. The resulting condition of the blanks was consistent with the expectations of this process.

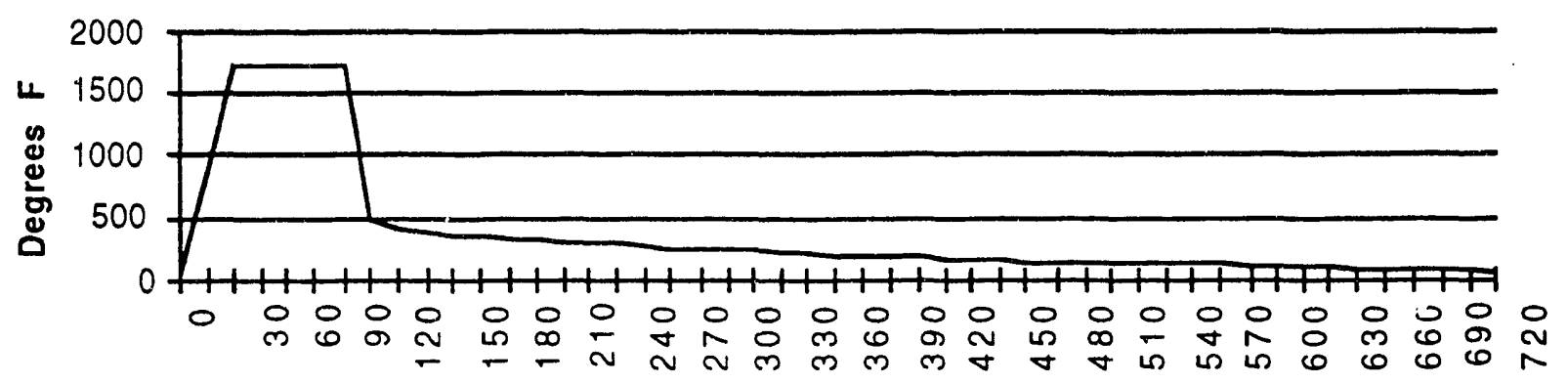

Minutes

Figure 27321 Stainless Steel Vacuum Anneal Cycle 


\subsubsection{Inconel - Cryogenic Stabilization}

The Inconel parts blanks were subjected to the cryogenic sequence described by figure 28 . Appreciable benefit could not be determined within the scope of this project.

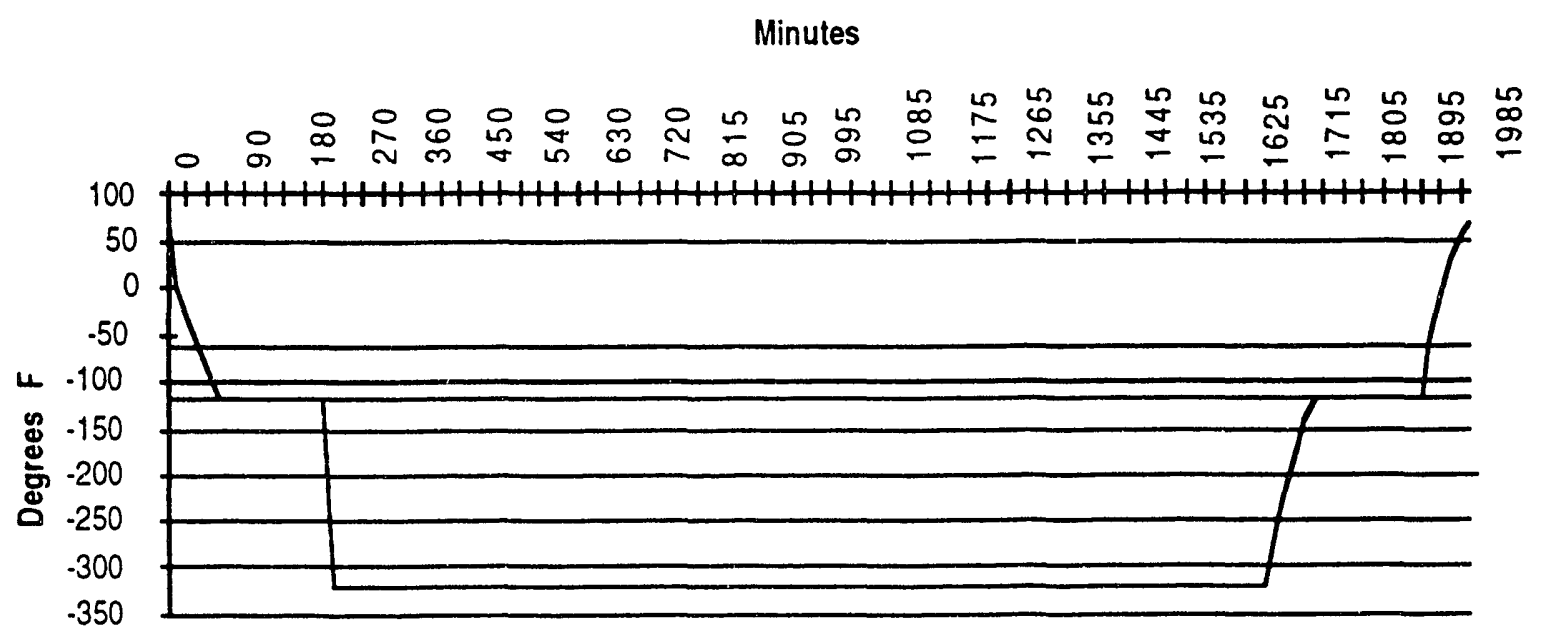

Figure 28718 Inconel Cryogenic Stabilization Cycle

\subsubsection{Finishing Operation (Inconel)}

Cylindrical grinding was identified as a suitable method of finishing the outer features of this component. Findings of this process investigation are presented in the following sections of this document.

The annealed blank was held in a collet on the solid portion of the .578 inch diameter, with three inches extending. Alignment of the blank, though not crucial at this time, was assured by indicating and adjusting any discrepancy at both ends of the exposed blank. This effort at alignment was intended to alleviate potential difficulties in the following operations.

The inner bore was finished using a $3 / 8$ inch diameter solid carbide boring bar with a triangular shaped K-313 insert. The insert had a .005 inch radius on the cutting tip and a 30 degree back rake which was ground onto the insert to enhance the chip flow characteristics of the insert.

\begin{tabular}{|cccc|}
\hline SFM Work Speed & IPR Feed Rale & Depth of Cut (inch) & Tool Designation \\
100 &.$(0) !$ & .005 & K-313 \\
\hline
\end{tabular}

Table 16: Finish Machining Parameters for the .4774 inch diameter bore of the Inconel Component

A Weldon CNC cylindrical grinder was used initially to attempt finishing the tightly toleranced outer features. A tooling mandrel was ground, and the Inconel blank mounted on the mandrel. Driving force and support was achieved by using the tail stock of the grinder.

Finish grinding of all external features, diameters, tapers and the spherical radius was attempted during the first operation. The initial results showed good surface finish on the diameters, however the taper and radius did not finish to an acceptable level.

A second grinding theory, grinding each feature independently of the others, proved unacceptable. Break out of the inner bore occurred during this process causing a rethinking of the process. Examination of our second part revealed evidence of two suspected problems. The inner diameter was getting larger as material was ground from the outer surface, residual stresses from the roughing operation were thought to cause of this situation. The other area of suspicion was 
the grinding relief put into the blank in the roughing operation. The tail stock pressure was great enough to cause the blank to llex at the relict, allowing the part to continuously pull into the grinding wheel, causing a greater depth of cut. This constant flexing is also thought to be a source of stress build up in the blank during the finishing operation.

\begin{tabular}{|llll|}
\hline SFM Work Speed & IPR Feed Rate & Depth of Cut & Wheel Designation \\
$150 \mathrm{RPM}$ & 5 IPM & .0001 & Norton 60 \\
\hline
\end{tabular}

Table 17: $\quad$ Parameters for the CNC Weldon grinder process

Lack of ideal tooling and configuration of the CNC grinder led to the consideration of a conventional cylindrical grinder. A Brown and Sharpe Number two grinder was considered our best available machine to continue this process investigation.

Attempting to rnachine the blanks between centers was chosen as the suitable method of part fixturing for this operation. Hardened support pins were made to fit the inner diameter of the blanks, a tooling center was dressed in a center grinder after the pins were hardened. The tailstock center was redressed in the machine to provide optimum alignment between the support pin and blank configuration and the tailstock.

A wall thickness of .007 inch was attained prior to the inner bore increasing in size. Considerable effort was made to provide mandrel support in pursuit of the specified .005 inch wall thickness. Successively larger support pins were required as the inner bore continued to enlarge when work was done on the outer features. The resulting parts were not within the prescribed tolerances, resulting in the decision to pursue Stainless Steel as the subsequent material of choice for this component.

\begin{tabular}{|llll|}
\hline SFM Work Speed & IPR Feed Rate & Depth of Cut & Wheel Designation \\
150 RPM & 5 IPM & .0002 & Norton 32A 46J* \\
\hline
\end{tabular}

Table 18: $\quad$ Parameters for the Brown and Sharpe conventional process

* Dressed to .600 inch wide, suggested to relieve to .25 inch

\subsubsection{Recommendation}

Results of these investigations preclude grinding as available process in the precision production of this cryocooler component. We acknowledge differing results may be attained with a more thorough study done in conjunction with persons possessing a more applicable experience base.

Processes developed for the Stainless Steel components (detailed in section 5.2.7) are very promising. We recommend the application of these processes in an attempt to produce an acceptable component from Inconel.

\subsubsection{Finishing Operation (Stainless Steel)}

\subsubsection{Method 1}

The annealed blank was held in a collet on the solid portion of the .578 inch diameter, with three inches extending. Alignment of the blank, though not crucial at this time, was assured by indicating and adjusting any discrepancy at both ends of the exposed blank. This effort at alignment was intended to alleviate potential difficulties in the following operations.

The inner bore was finished using a $3 / 8$ inch diameter solid carbide boring bar with a triangular shaped K-313 insert. The insert had a .005 inch radius on the cutting tip and a 30 degree back rake which was ground onto the insert to enhance the chip flow characteristics of the insert. Lead 
tape was fixed to the outer diameter to dampen the machining vibrations generated in finishing the inner diameter.

\begin{tabular}{|cccc|}
\hline SFM Work Speed & IPR Feed Rate & Depth of Cut (in.) & Tool Designation \\
160 & .001 & .005 & $\mathrm{~K}-313$ \\
\hline
\end{tabular}

Table 19: Finish Machining Parameters for the .4774 inch diameter bore of the Stainless Steel Component (Method 1)

The .4843 outer diameter was finished following the completion of the bore. A mandrel was placed in the bore and supported by the tail stock of the lathe. This provides the backing necessary to machine to thin walled configurations. Light cuts with continuous feed of the tool are required to minimize the amount of stress introduced into the component.

\begin{tabular}{|cccc|}
\hline $\begin{array}{c}\text { SFM Work Speed } \\
160\end{array}$ & IPR Feed Rate & Depth of Cut (in.) & Tool Designation \\
\hline
\end{tabular}

Table 20: $\quad$ Finish machining parameters for the .4843 outer diameter

* VC-29 grade carbide in 55 degree configuration with a .01 inch nose radius. An after market, 30 degree positive back rake was ground onto this insert to reduce cutting pressure.

The blank was then held in a V-block registering on the finished .4843 diameter, the blank's tooling center was redressed in a center grinder to assure coincident centerlines of these two features prior to finishing the remaining outer features. A CNC lathe was used for the finishing operation.

A support pin was placed in the finished hore prior to gripping the solid portion of the .4843 diameter lightly in a collet. A floating center (figure 29) was used to apply driving pressure to the part during this turning operation. The lloating center method reduces the affects of misalignment factors found in the hlank or machine, resulting in the optimum conditions for achieving the close tolerances specilied lor this component. The finish machining of the remaining diameters, 3() .25 degrec conic section and the spherical radius was done during this operation. Alignment was verilied using an electronic indicator.

$\begin{array}{cccc}\text { SFM Work Speed } & \text { IPR Feed Rate } & \text { Depth of Cut (inch) } & \text { Tool Designation } \\ 160 & .002 & .005 & \text { VC-29* }\end{array}$

Table 21: Parameters for Finishing Outer Features of the Stainless Steel Component

* VC-29 grade carbide in 55 degree configuration with a .01 inch nose radius. An after market, 30 degree positive back rake was ground onto this insert to reduce cutting pressure.

The .068 inch diameter holes were machined using conventional LLNL manufacturing practices. The hole drilling operation has the potential for raising material at the hole and spherical radius interface, causing a violation of the true position tolerance of the .250 radius. An awareness of this possibility, as stated earlier, is crucial in producing a quality component. 


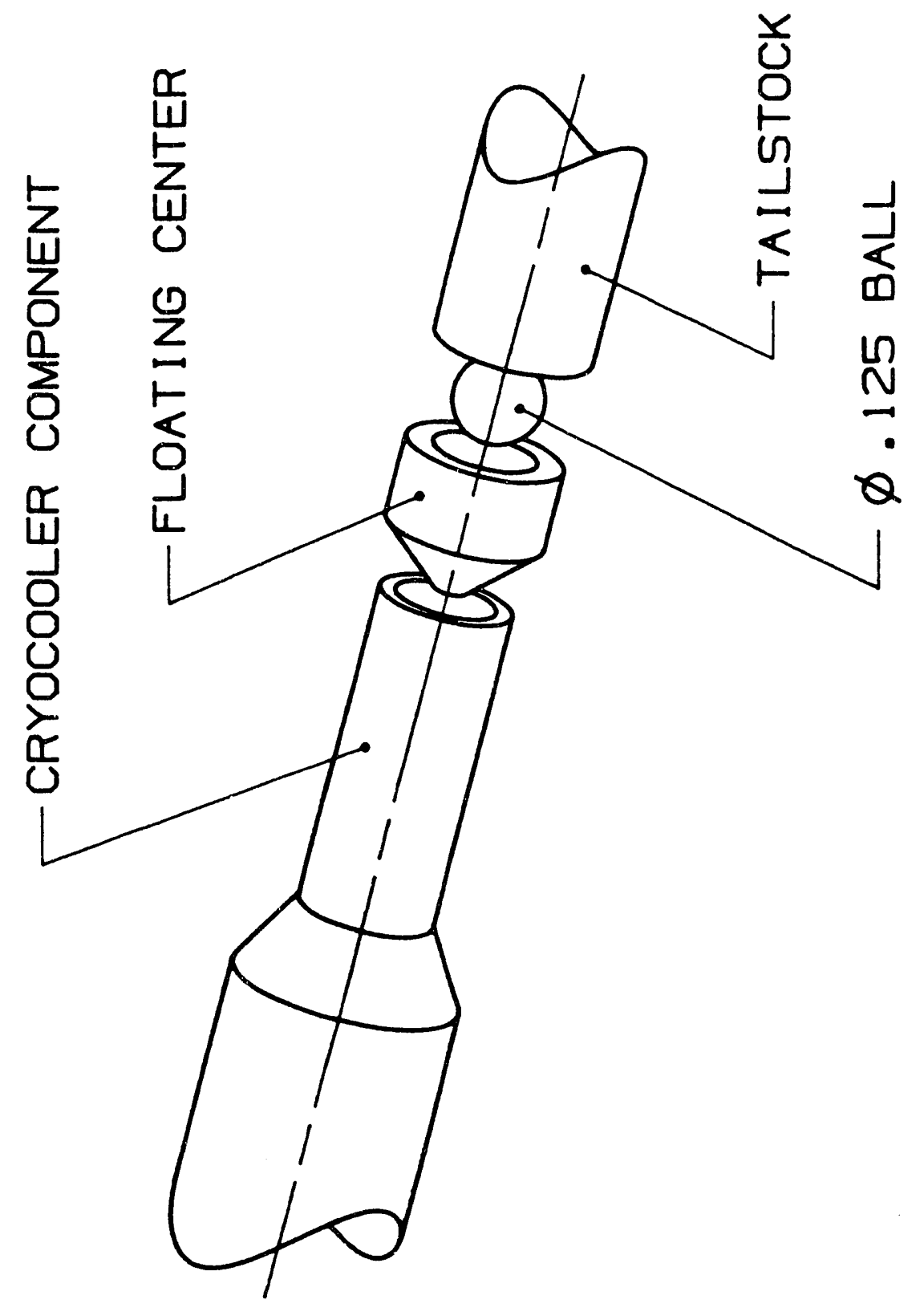

造 
The annealed blank was held in a V-block, registering on the skimmed .578 diameter, to redress the ivoling center in a center grinder to assure alignment of these two features prior to the first finishing operation step.

The blank was then held in a .578 inch (37/64) collet with $31 / 8$ inches of the smaller diameter end protruding. The floating center (figure 29) was employed to apply noninfluential driving force to the part during this turning operation. The floating center method reduces the affects of misalignment factors found in the blank or machine, resulting in the optimum conditions for achieving the close tolerances specified for this component. Alignment was verified using an electronic indicator.

The .2500 and .185 diameters, spherical radius and conic section were firished at this time. Prior to the final .01 inch being removed, the tooling center redressing proce's was repeated, assuring minimal impact of misalignment issues. The minimization of additiona' stresses in the blank was achieved by using sharp tools, small depths of cut (.005 inch) and light but continual feed rates. The .4843 diameter was finished to within approximately .100 inch of the depth of the .4744 diameter bore. This process was used to avoid stressing the thin wall section of the blank during this phase of the finishing operatior.

A split fixture (figure 3() ) was built to support the .250 and .4843 diameters during the remaining turning operations. Clamping forcis of the lixture were limited to the .4843 diameter. The inner bore was semi-linished using a $3 / 8$ inch diameler solid carbide boring bar with a triangular shaped $r-313$ insert. The insert had a .(1)5 inch radius on the cutting tip and a 30 degree back rake which was ground onto the insert to enhance the chip flow characteristics of the insert. The finishing passes were taken with a K-68 grade insert. Lead tape was fixed to the outer diameter to dampen the machining vibrations generated in finishing the inner diameter.

\begin{tabular}{|cccc|}
\hline SFM Work Speed & IPR Feed Rate & Depth of Cut (inch) & Tool Designation \\
160 & .002 & .005 & $\mathrm{~K}-68^{*}$ \\
\hline
\end{tabular}

Table 22: $\quad$ Bore Finishing Parameters for 321 Stainless Steel (Method 2)

* K-68 grade carbide in a triangular configuration with a .007 inch nose radius and 30 degree positive back rake to reduce cutting pressure through improved chip flow characteristics.

The outer fi.lishing process was aided by placing a support pin, .0002 inch smaller than the finished inner bore, to provide support during the finishing of the outer diameter. The pin was designed to provide a driving force to the 10 degree angled base of the inner bore. A tooling center in the support pin provided for the tailstock engagement to provide this force. The .4844 diameter, finished in this configuration, was turned with a minimum disruption of existing features by employing sharp tools, small depths of cut (.005) and light but continual feed rates.

\begin{tabular}{|cccc|}
\hline $\begin{array}{c}\text { SFM Work Speed } \\
1(10\end{array}$ & IPR Feed Rate & Depth of Cut (inch) & Tool Designation \\
.$(0) 1$ & .005 & VC-29* \\
\hline
\end{tabular}

Table 23: $\quad$ Outer Fcalure Finishing Prameters (Met'od 2)

* VC-29 grade carbide in 55 degree configuration with a .01 inch nose radius. An after market, 30 degree positive back rake was ground onto this insert to reduce cutting pressure. 


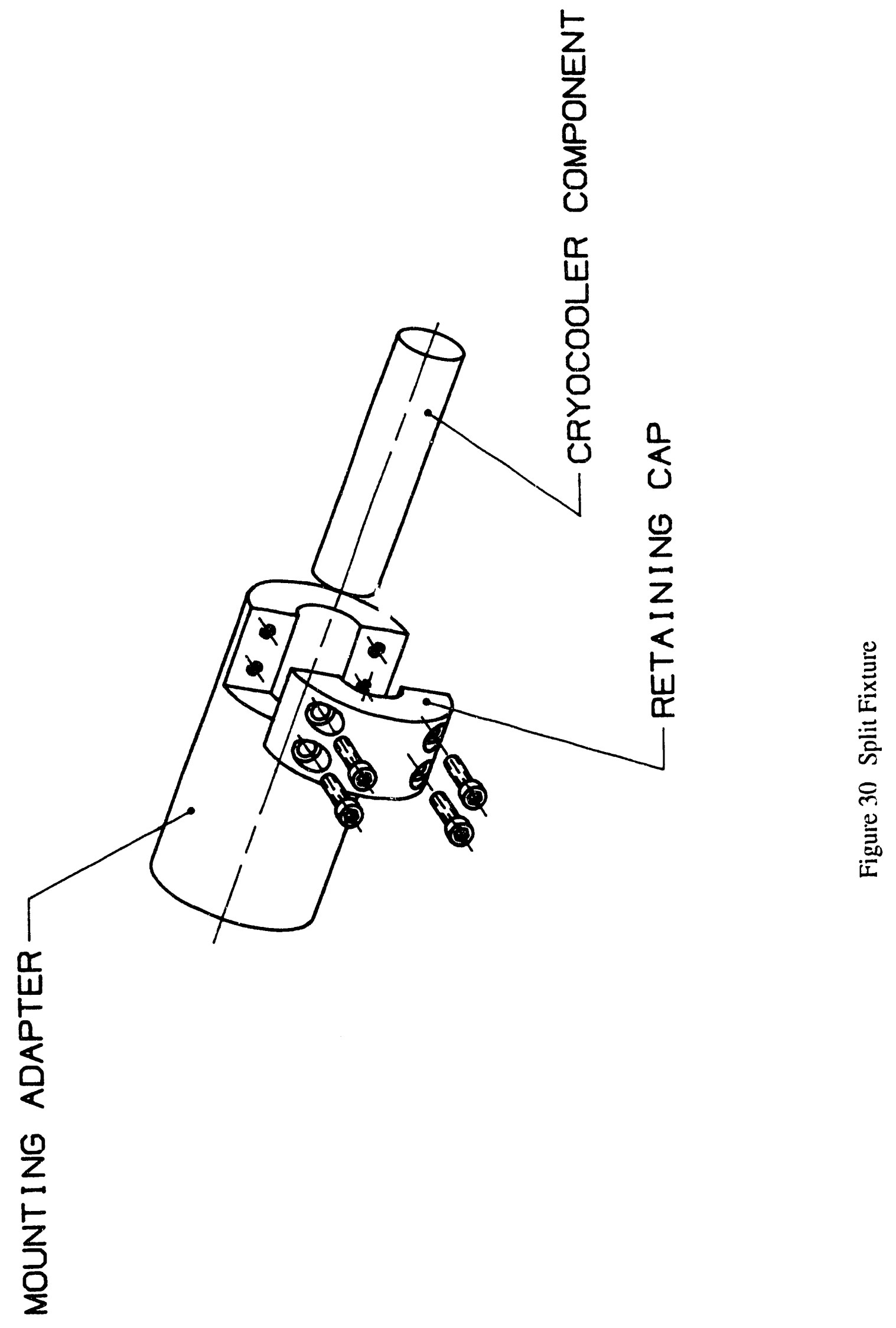




\subsubsection{Inspection}

\subsubsection{Diametrical Size Determination}

The thin wall section necessitated the use of the non-contact LaserMike, which may be used to inspect the other outer diameters. Most outer diametrical dimensions can also be determined with a conventional micrometer.

Air gaging was used to measure the thin wall section inner diameter. The smaller diameters, being less fragile, were inspected with gage pins.

\subsubsection{Runout Measurement Process}

LLNL's Bendix Indi-Ron roundness gage was used to inspect the runout condition of the component. A small diameter, .O()1 inch stylus probe tip is recommended because it minimizes the effects of airborne contaminates.

Polar charts (figure 26) were generated for all diameters with a runout tolerance. All total runout measurements will need polar charts generated at one-half inch increments. When the cylinder is less than one half inch long, a chart at the top and bottom of the cylinder is required.

The polar chart was oriented to the zero degree position. Using a flow ball pen, a mark was placed on the part. This index mark provided the necessary correlation of chart data to the location of the measurement.

The part was held in a V-Block on the Indi-Ron table. Datums -A- and -B- were aligned and a polar chart was generated to document the concentricity of the two diameters.

The exterior and interior diameters were probed for at this time. Polar charts, at one-half inch increments, were taken of all diametrical features with associated runout tolerances.

Three radial traces, at varying heights on the .25 inch spherical radius, were made to determine its runout to the datums.

Datums - A- and -B- were reinspected to verify their positioning had remained constant through this process. A polar chart was generated to document their position.

Straightness checks were made to corrclate the polar chart data. This was done on a Federal Surfanalyzer.

All charts must be marked clearly and completely with information relating to part serial number, location of measurement, and feature being measured.

\subsubsection{Linear Feature Verification}

All external linear, angular, and radii features were measured and recorded with an optical comparator.

Internal radii and angles were transferred to a dental impression material. An optical comparator was then used to check these features.

Depth dimensions were checked with a conventional depth micrometer. 


\section{V1. costs}

MODIL Demonstration Project costs are presented in a man-hours format that separates costs for the development, production and demonstration phases of the project (figure 31).

The Inconel component machining development process did not reach the production phases.

This is illustrated with only one bar on the graph. Information detailing this development process is in section 5.2.6.1 of this report.

The stainless steel component process development was achieved in major part by capitalizing the information derived from the Inconel component process development effort.

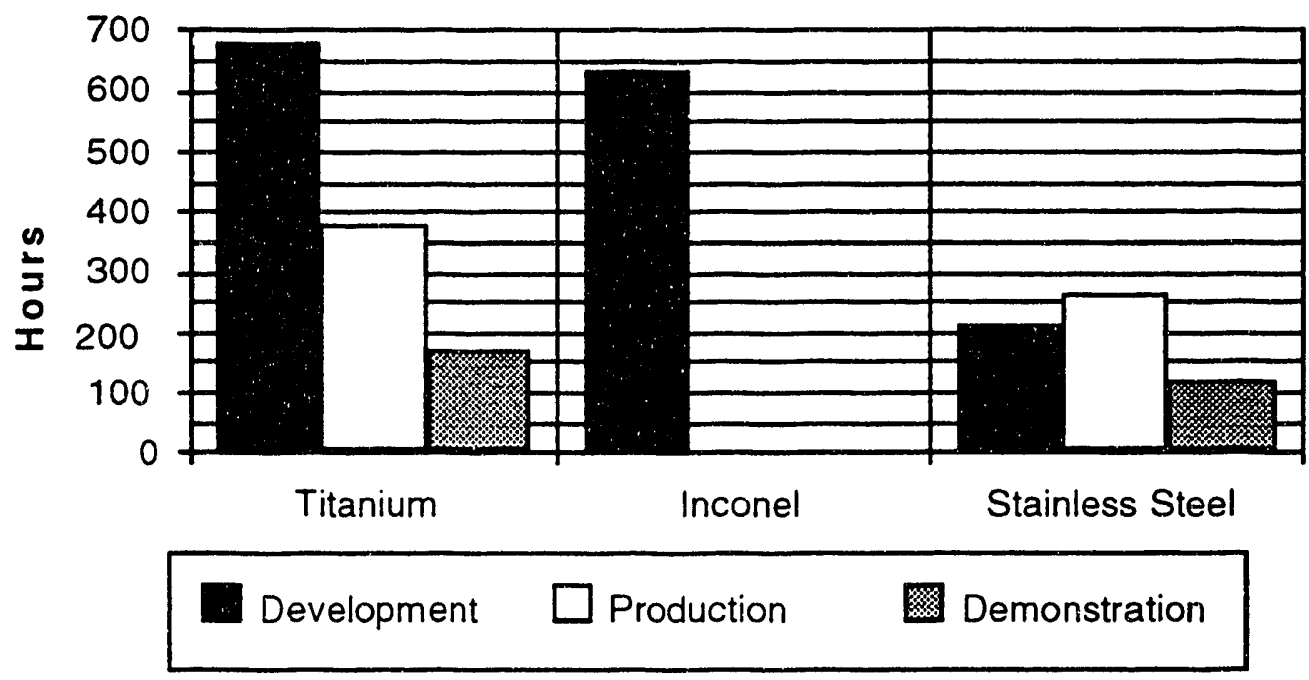

Figure 31 Hours/Component/Phase Comparison

\section{1}

First Briefing to Industry

On September 23-24, 1993, an industry-wide briefing was hosted by SDIO's Spacecraft Fabrication and Test MODIL at LLNL. The over 100 attendees represented a broad spectrum of aerospace industry involved in producing SDIO systems, as well as many key representatives from SDIO programs (BE, GBI, BP, etc.). The briefing included numerous presentations, working sub-sessions, and tours of MODIL applicable, potentially applicable, and showcase facilities.

The briefing had two major objectives:

- To explain the objectives and progress of the SF\&T MODIL and

- To present LLNL technology applied to current MODIL thrusts, as well as, key technology of potential henefit to SDIO programs.

The cryocooler thrust area subsession consisted of four presentations which are as follows:

- Cryocooler MODIL Thrust Area Subsession

- Producibility for Cryocoolers FY93

- MODIL Demonstration, Material Fabrication Division Phase

- Partnership with the California Community Colleges, Centers for Applied Technologies

Details of the briefing are published in the proceedings 3 . 


\section{CONCILUSIONS AND RECOMMENDATIONS}

Through the contractor, supplier, and LLNL project summary meetings, many issues were raised that offered solutions to producibility problems encountered within the design/manufacturing environment. The results of the producibility demonstration project illustrated the need to consider and to implement changes in the current method of operation in the production community.

Following are recommendations that surfaced in our working interaction and meetings with the participating contractors, their suppliers, and the LLNL producibility teams:

- Make sure all parties involved know what the project goals are and what's expected of them.

- Involve all participants in the whole project (from beginning to end), solicit their ideas from the beginning (engineering, manufacturing, QA, purchasing, etc.). Brainstorming is a must.

- Engineering staff should share floor time with machinist to understand what it takes to make parts.

- Ideas have to be readily accepted for consideration without personal bias.

- Teams assigned to the project are most efficient and cost effective when maintained as an entity throughout the project.

- Evaluate every manufacturing option to optimize project end-product.

- LLNL is a resource for manufacturing technology available to US industry.

- Minimize inspection by building robustness into parts and controlling the manufacturing process. Spend the time needed in the design phase.

- Design reviews must include all parties to ensure the drawings are as correct as possible helore parts are manufactured. Pre-production design changes have a lesser financial impact than making changes during manufacturing.

The results of this demonstration project demonstrated that precision production issues can and should be addressed early in the design phase of any project. Concurrent engineering practices do work! 


\section{PROJECT CLOSE-OUT MEETING SUMMARIES}

1. Gilbert E. Cruz, "Creare/Westfield Gage/LLNL Demo Project Close-Out Meeting", Dec 1992, 92-249, LLNL.

2. Gilbert E. Cruz, "Hughes Aircrafu/Modern Industries/LLNL Demo Project Close-Out Meeting", Dec 1992, 92-250, LLNL. 
Mail Station L - 332

Ext: $2-4849$

December 1, 1992

92-249

To: $\quad$ Distribution

From: $\quad$ G. E. Cruz

Subject: Creare/Westfield Gage/LINL Demo Project Close-Out Meeting

The guidelines for the meeting were that it was to be an open, candid and issue oriented meeting with the purpose of summarizing the LLNL Producibility Demonstration Project results with LLNL, Creare and Westfield Gage. Issues raised are to be used to help improve the production capabilities of Westfield Gage in addition to other U.S. companies that can use the information. Creare will continue to be a contract $R \& D$ company and not work production issues.

The key issue of the demo project was to demonstrate the vital need for companies to employ concurrent engineering techniques within their respective companies. The salient point of the interactions is the early-on and continuous communication between all the parties involved in the production of a product through to the end of the project.

The demo project began slowly because of a number of issues. A key issue being that everyone did not know each other and a working relationship had to be established between all of the involved parties.

Other impediments were: a lack of a full understanding about the project goals, what each company would get out of the project, and what the boundary conditions of the project were.

Once the project settled into a working entity, the communication between all of the parties was very good and candid. Each party communicated openly with one another and at the time this began, progress was achieved. Ideas and problem solutions transferred back and forth rapidly, both LLNL and Westfield Gage learned things from one another. By working in close proximity, information was shared first hand, therefore, facilitating better comprehension of the problems and their solutions. It was learned that to better transfer technology it is optimal to be in close proximity where issues and questions can be addressed in real time. Another fact that was learned was that mutual trust amongst the involved parties is necessary to succeed. This takes personal contact. Westfield Gage demonstrated this with LLNL and Creare during this project and because of this

University of California

University of catiomia 
attitude, the project was a success. What is being shown is that any company has to work closely and openly with their suppliers if they are to be successful.

The project demonstrated that the complete goals of the project need to be presented to the project participants at the beginning of the project and that the designers, machinists, technicians, etc. need to have access to the engineering and scientific staff throughout the project in order to mitigate risk, cost, schedule and production problems.

Project teams must be maintained throughout the project for continuity. Rotating participants in and out of the project creates confusion, schedule delays and extensive learning curve effects.

Tabulated inspection data needs to be documented to efficiently track the results of in-process work and to produce the highest quality end product.

The inspection work between LLNL and Westfield Gage validated the inspection techniques at Westfield Gage.

The Laboratory did not utilize the full extent of MFD capability because processes were to be developed utilizing only the machines comparable to what industry has. Developing a process on state-of-the-art equipment would not help industry, who in most cases does not possess this type of equipment.

A key technical issue learned by all was the importance of using non-contact inspection techniques (i.e., air gauging, laser micrometer) on thin wall, precision toleranced parts. The results are more accurate and repeatable. In addition, using EDM techniques to machine internal diameters was presented. Westfield had not considered using EDM for this application. Westfield Gage learned, through the close interaction with the LLNL people, the importance of controlling the EDM machine operating parameters (water conductivity, etc.) in order to be able to produce continually high quality parts. Westfield is considering how they work projects and what changes could be made to optimize their operation (e.g., involving shop floor people in early-on project planning).

The LLNL machinists learned the benefit of using machines with adjustable tail stocks.

One institutional problem arose that caused problems. The procurement and contracts procedure caused delays with the project start-up. The major issue is that if LLNL wants to effectively work with outside companies the in-house process has to be optimized.

These issues were the primary subject brought up at the meeting. There were others, however, they were variations of communications and techniques learned, which was previously mentioned. 
In summary, time and money constraints dictated certain requirements of this project, therefore, the project scope was limited to a goal that could readily be achieved. That goal was to focus on the process of concurrent engineering in a manufacturing environment.

The success of the program was dependent upon demonstrating a tangible result that could be readily understood. Our results demonstrated this. Creare and Westfield Gage were very instrumental in the success of this project. They are helping to prevent the Laboratory from being the nation's best secret; they realize that LLNL is a resource to industry and are looking for ways to work with the Laboratory.

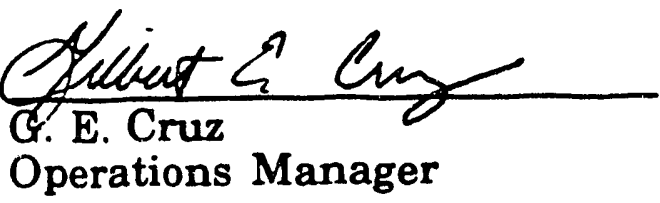

GEC:jsc

Distribution: Benedict, John

Franks, Mark

Locke, Susan

Patterson, Dick (Westfield Gage)

Prokosch, Mike

Stearns, Bob (Creare)

Yordy, Don 


\section{MATERIALS FABRICATION DIVISION}

Mail Station $L \cdot 332$

Ext: $2-4849$

December 1, 1992

92-250
To:
Distribution
From:
G. E. Cruz

Subject:

Hughes Aircraft/Modern Industries/LNL Demo Project Cloee-Out Meeting

The guidelines for the meeting were that it was to be an open, candid and issue oriented meeting with the purpose of summarizing the LLNL Producibility Demonstration Project results with LLNL, Hughes Aircraft and Modern Industries. Issues raised are to be used to help improve the production capabilities of each company in addition to other U.S. companies that can use the information.

The key issue of the demo project was to demonstrate the vital need for companies to employ concurrent engineering techniques within their respective companjes. The salient point of the interactions is the early-on and continuous communication between all the parties involved in the production of a product through to the end of the project.

The demo project began slowly because of a number of issues. A key issue being that everyone did not know each other and a working relationship had to be established between all of the involved parties.

Other impediments were: a lack of a full understanding about the project goals, what each company would get out of the project, and what the boundary conditions of the project were.

Once the project settled into a working entity, the communication between all of the parties was very good and candid. Each party communicated openly with one another and at the time this began, progress was achieved. Ideas and problem solutions transferred back and forth rapidly, both LLNL and Modern Industries learned things from one another. By working in close proximity, information was shared first hand, therefore, facilitating better comprehension of the problems and their solutions. It was learned that to better transfer technology it is optimal to be in close proximity where issues and questions can be addressed in real time. Another fact that was learned was that mutual trust amongst the involved parties is necessary to succeed. This takes personal contact. Modern Industries demonstrated this with LLNL and Hughes during this project and because of this attitude, the project was a success. What is being shown is that any company has to work closely and openly with their suppliers if they are to be successful.

The project demonstrated that the complete goals of the project need to be presented to the project participants at the beginning of the project and that the designers, machinists, technicians, etc. need to have access to the engineering and scientific staff throughout the project in order to mitigate risk, cost, schedule and production problems. 
Project teams must be maintained throughout the project for continuity. Rotating participants in and out of the project creates confusion, schedule delays and extensive learning curve effects.

Tabulated inspection data needs to be documented to efficiently track the results of in-process work and to produce the highest quality end product.

The inspection work between LLNL and Modern Industries validated the inspection techniques at Modern Industries.

The Laboratory did not utilize the full extent of MFD capability because processes were to be developed utilizing only the machines comparable to what industry has. Developing a process on state-of-the-art equipment would not help industry, who in most cases does not possess this type of equipment.

A key technical issue learned by all was the importance of using non-contact inspection techniques on thin wall, precision toleranced parts. The results are more accurate and repeatable.

These issues were the primary subject brought up at the meeting. There were others, however, they were variations of communications and techniques learned, which was previously mentioned. whe

In summary, time and money constraints dictated certain requirements of this project, therefore, the project scope was limited to a goal that could readily be achieved. That goal was to focus on the process of concurrent engineering in a manufacturing environment.

The success of the program was dependent upon demonstrating a tangible result that could be readily understood. Our results demonstrated this. Hughes and Modern Industries were very instrumental in the success of this project. They are helping to prevent the Laboratory from being the nation's best secret; they realize that LLNL is a resource to industry.

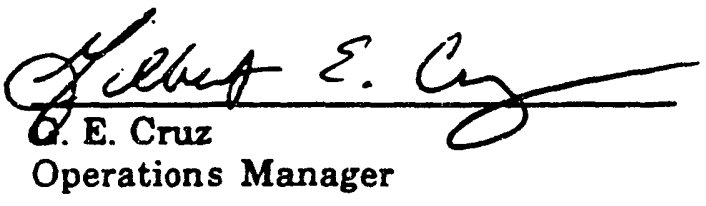

GEC:jsc

Distribution: Benton, Terry

Daniel, Jack (Modern Industries)

Fasholz, Dick

Franks, Mark

Gresko, Laurence (Hughes Aircraft)

Harkov, Dewayne

Neville, Steve (Hughes Aircraft)

Peters, Charles

Prokosch, Michael

Rose, Kevin (Modern Industries)

Saito, Ted

Yahraus, Dan (Modern Industries) 


\section{REFERENCE MATERIAL}

\section{Glossary}

EDM: Electrical Discharge Machining, a process involving the charging of an electrode and its subsequent discharge to the work piece. Variation of the charge determines the amount of cutting action at the electrode/work piece interface. Plunge or sinker EDM machines duplicate the electrode shape in the part. The electrode may be completely through the part or stop at any level into the part (blind hole). Traveling wire EDM allows a computer to direct the work piece under the wire to cut intricate shapes. The nature of wire EDM requires that the wire is allowed to pass through the part in a straight line.

IPR: Inches per Revolution, a common measure of the speed which a cutting tool moves across a work piece. Typically used in lathe operations.

IPT: Inches per Tooth, a common measure of cutting efficiency for drills or milling cutters.

MODIL: Manufacturing Operation Development and Integration Laboratory

SFM: $\quad$ Surface Feet per Minute, a measure of the amount of surface passing a cutting tool.

Siemens: The electrical conductance of a conductor in which a current of one ampere is produced by an electric potential difference of one volt. One siemens is the reciprocal of one ohm.

\section{References}

1. Gilbert E. Cruz, Theodore T. Saito, Larry Fehrenbacher, TATI, “Cryocooler Producibility within a MODIL Concept”, Apr 1992, UCRL-JC-110272, LLNL.

2. Pete Paulin, "Mechanisms and Applicability of Heat Treating at Cryogenic Temperatures", Industrial Heating, Aug 1992, pp. 24-27, 300 Below Inc., Decatur, IL.

3. Theodore T. Saito, "Proceedings, Spacecraft Fabrication and Test MODIL, First Briefing to Industry", September 23-24, 1993, Vol. 1, Oct, 1992. 

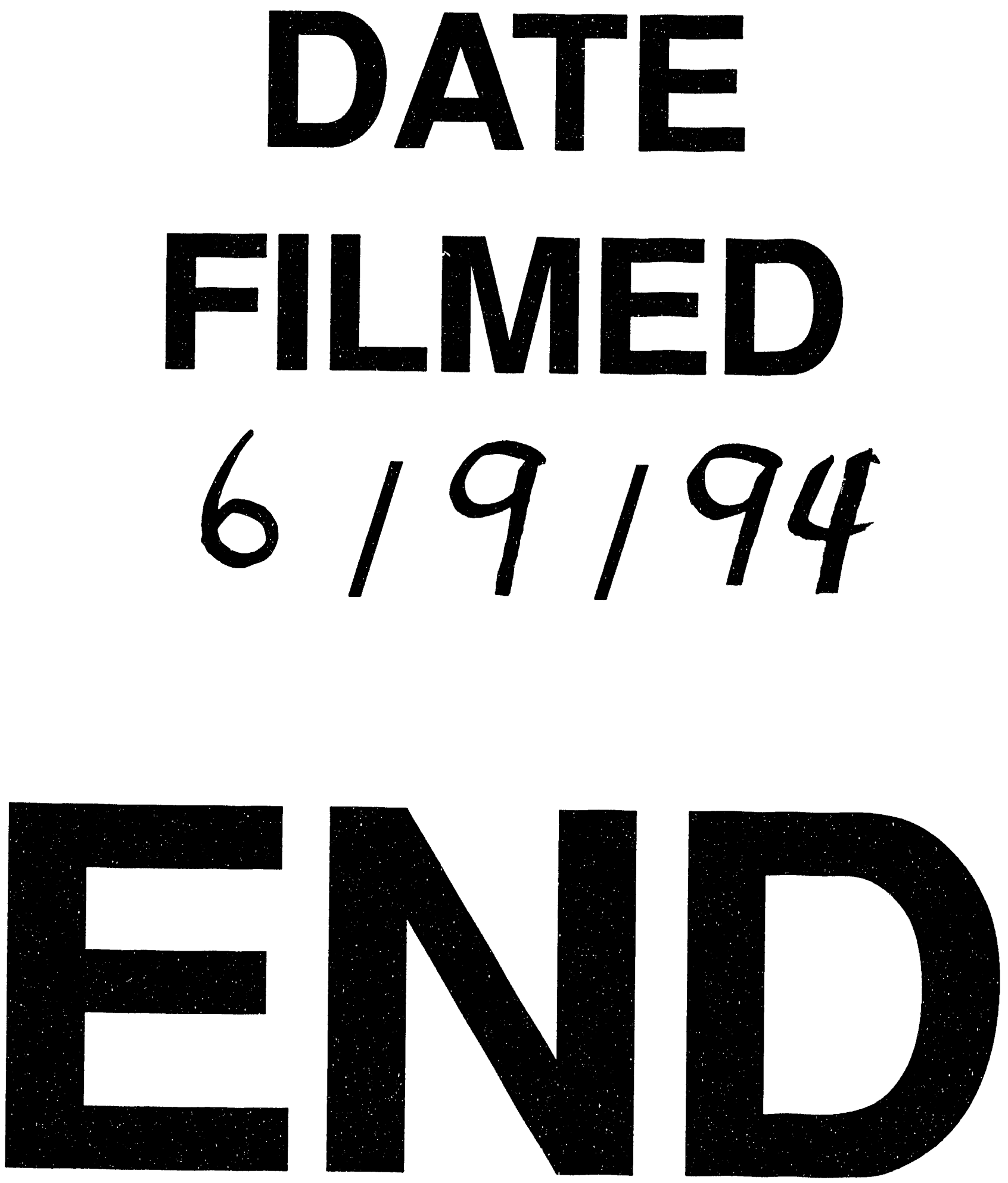
